\title{
Ultrathin Solar Cells Based on Atomic Layer Deposition of Cubic versus Orthorhombic Tin Monosulfide
}

\author{
Andrii A. Voznyi, Oleksandr V. Bilousov, Björn Landeke-Wilsmark, Jan Keller, Jie Ren, Shi-Li Zhang, \\ and Carl Hägglund*
}

Cite This: ACS Appl. Energy Mater. 2021, 4, 8085-8097

Read Online

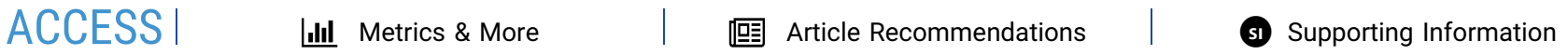

ABSTRACT: Tin monosulfide can be grown in cubic $(\pi$-SnS) and orthorhombic $(\alpha$-SnS $)$ polymorphs by low-temperature atomic layer deposition (ALD). The optical properties of these polymorphs make them attractive for the realization of plasmonic solar cells with ultrathin absorber layers down to $10 \mathrm{~nm}$ in thickness. $\mathrm{SnS}$ is also an earth-abundant and nontoxic compound semiconductor of high interest for regular thin-film photovoltaics. To better understand the behavior of the two SnS polymorphs in ultrathin solar cell configurations, we here fabricate, characterize, and analyze a range of such devices. ALD is used to grow $\mathrm{SnS}$ and form heterojunctions with zinc oxysulfide $[\mathrm{Zn}(\mathrm{O}, \mathrm{S})]$, acting as a buffer layer with a composition-tunable bandgap. Apart from the roles of the $\mathrm{SnS}$ polymorph and $\mathrm{Zn}(\mathrm{O}, \mathrm{S})$ composition, the effects of the back contact material and thicknesses of buffer and absorber layers are investigated.

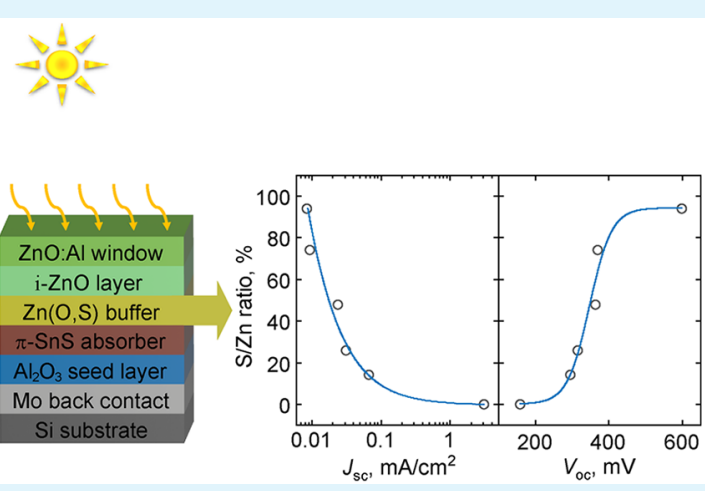
Devices using $\pi$-SnS and pure $\mathrm{ZnO}$ buffers yield the highest photocurrents $\left(3.1 \mathrm{~mA} / \mathrm{cm}^{2}\right)$ and higher open circuit voltage (159 $\left.\mathrm{mV}\right)$ than similar $\alpha$-SnS-based devices. Analysis of the equivalent-circuit parameters suggests that interface recombination limits the voltage for these devices. While $\mathrm{Zn}(\mathrm{O}, \mathrm{S})$ with a higher sulfur content provides chemical passivation of the SnS interface and excessive open circuit voltages above $600 \mathrm{mV}$, it also exhibits a too high conduction band offset, which hampers current collection. A growth delay during the ALD of $\mathrm{Zn}(\mathrm{O}, \mathrm{S})$ on $\mathrm{SnS}$ initially amplifies the known sulfur-oxygen exchange reaction, such that a sulfurrich $\mathrm{Zn}(\mathrm{O}, \mathrm{S})$ region forms next to the $\mathrm{SnS}$ interface. This causes a thin $\mathrm{ZnS}$-like barrier to form already for low cycle fractions of the $\mathrm{H}_{2} \mathrm{~S}$ precursor in the ALD super-cycle. Voltage and fill factor trends suggest an optimal SnS absorber layer thickness in the range of $15-35 \mathrm{~nm}$, presenting an opportunity for plasmonic absorption enhancement. Devices with $\pi$-SnS show most promise, but interface recombination versus current-blocking is a dilemma for the $\mathrm{SnS} / \mathrm{Zn}(\mathrm{O}, \mathrm{S})$ heterojunction.

KEYWORDS: ultrathin film solar cells, cubic and orthorhombic SnS absorbers, atomic layer deposition, $\mathrm{Zn}(\mathrm{O}, \mathrm{S})$ buffer layers, equivalent-circuit modeling

\section{INTRODUCTION}

The development of efficient solar cells with absorber layers much thinner than the wavelengths of sunlight is attractive from several viewpoints. ${ }^{1}$ These include the higher solar cell performance enabled through increased quasi-Fermi-level splitting when charge carriers are generated at high density in ultrathin layers and a shorter distance to the charge separating junction. ${ }^{2}$ Increased throughput, reduced energy use, and decreased consumption of scarce and expensive materials in production are also important aspects. ${ }^{3,4}$ Ultimately, absorber layers down to $10 \mathrm{~nm}$ thickness are envisioned through plasmon near-field-enhancement and light management. ${ }^{5}$ Although the governing optics and basic operation of such devices are fairly established, ${ }^{6,7}$ the implementation of efficient current rectification and voltage generation in ultrathin absorber layers and optically suitable geometries can be more challenging than in regular thin-film solar cells because of close proximity to contact layers, limited band bending over the thin layer, pin holes, and other defects. Adverse recombination at the contact interfaces and the establishment of an adequate charge separating junction must be addressed specifically and in detail for the absorber material of choice. ${ }^{8}$

For exploitation of the plasmon near-field-enhancement in solar cells, two-dimensional arrays of noble metal nanoparticles coated by an ultrathin semiconductor layer are a very resourceefficient design., ${ }^{5,9}$ Tin monosulfide $(\mathrm{SnS})$ is of high interest in this context, as it is one of the relatively few materials suitable for photovoltaic absorber layers that can be grown by atomic

Received: May 12, 2021

Accepted: July 21, 2021

Published: August 4, 2021 
layer deposition (ALD) at low temperature. ${ }^{10,11}$ ALD coats metal nanoparticle arrays in a conformal manner and thereby approximates the core-shell geometry that is ideal for harvesting the plasmon near-field in solar cells. ${ }^{5}$ Another important advantage of $\mathrm{SnS}$ is that it has an exceptionally high imaginary part of the permittivity, which mitigates parasitic absorption in this type of system. ${ }^{6}$

More generally, thin-film photovoltaics based on $\mathrm{SnS}$ is intensely researched, as $\mathrm{SnS}$ is considered a promising, earth abundant, and nontoxic alternative to the more established $\mathrm{CdTe}, \mathrm{CuInSe}_{2}$, or $\mathrm{Cu}(\mathrm{In}, \mathrm{Ga})(\mathrm{S}, \mathrm{Se})_{2}$ (CIGS) thin-film solar cell absorbers. ${ }^{12-15}$ Owing to the high absorption coefficient and near-optimal bandgap in the range of $1.1-1.3 \mathrm{eV}$ for the orthorhombic phase SnS ( $\alpha$-SnS $),{ }^{16,17}$ a high efficiency may in theory be approached. ${ }^{18}$ Recent studies have established that $\mathrm{SnS}$ may also crystalize in a cubic polymorph $(\pi-\mathrm{SnS}),{ }^{19-21}$ characterized by a wider bandgap of $1.6-1.8 \mathrm{eV}^{22,23}$ This is a near perfect match for an inorganic top cell in tandem with a silicon bottom cell, or indeed, with an $\alpha$-SnS-based bottom cell. $^{24,25}$

Despite these prospects, the current record efficiency of a $\mathrm{SnS}$ solar cell, achieved with the more researched $\alpha-\operatorname{SnS}$ phase, is below 5\%. ${ }^{11,26}$ Tentative bottlenecks for the performance include nonhomogeneity of the SnS material and its interfaces because of formation of secondary phases, along with the presence of different types of defects, altogether resulting in enhanced recombination rates. ${ }^{12,27}$ In addition, $\alpha$-SnS is structurally (and hence electronically and optically) anisotropic, which complicates its application in electronic devices. ${ }^{28}$ Another important aspect is that SnS-based solar cells often rely on device structures established for other, more common thin-film solar cell materials such as CIGS. ${ }^{29-31}$ The interface properties and band alignment of these configurations are not necessarily optimal. Studies have indeed pointed to an unusually low ionization potential resulting in wide conduction band offsets (CBOs) for $\mathrm{SnS}$ devices in typical thin-film solar cell stacks. ${ }^{16,32}$ Yet other research ascribes the main issue to a strong Fermi-level pinning, which prevents appropriate $\mathrm{CBO}$ and band bending to be established at the front junction. ${ }^{33,34}$

The aim of the current work is twofold. A first objective is to explore $\mathrm{SnS}$ as an optically ultrathin solar cell absorber, with its utilization in plasmonic solar cells as the long-term goal. We thus target $\mathrm{SnS}$ layer thicknesses much below the optical penetration depth. Because of the lack of light management, this inevitably leads to substantial absorption losses. However, by keeping the system relatively simple and consistent with previous work on $\mathrm{SnS}$ solar cells, we primarily aim to elucidate how the SnS thickness affects charge transport and device performance beyond the optics here. A second objective is to investigate the solar cell behavior of the relatively unexplored cubic $\mathrm{SnS}$ polymorph and to compare it to the more commonly employed orthorhombic polymorph. To do this, we make use of the recent finding that the $\mathrm{SnS}$ phase resulting from ALD can be very well controlled by means of substrate surface modifications. ${ }^{35}$ We compare several back contact materials $(\mathrm{Mo}, \mathrm{Ti}$, and $\mathrm{Al}$ ) and compositions of the $\mathrm{Zn}(\mathrm{O}, \mathrm{S})$ buffer layer in terms of their effects on the photovoltaic behavior. As $\pi$-SnS is less researched compared to $\alpha$-SnS for photovoltaic applications, the behavior of $\pi$-SnS devices is explored in more detail, including influences of absorber and buffer layer thicknesses.

\section{METHODS}

2.1. Device Fabrication. Thin-film solar cells were fabricated on $25 \times 20 \mathrm{~mm} \mathrm{Si}(100)$ wafer substrates (phosphorus doped, 1-10 $\Omega$ $\mathrm{cm}$, Sil'tronix, used as received), by deposition of a solar cell stack (Figure 1) consisting of a back metal contact ( $\mathrm{Mo}, \mathrm{Ti}$, or $\mathrm{Al}$ ), an

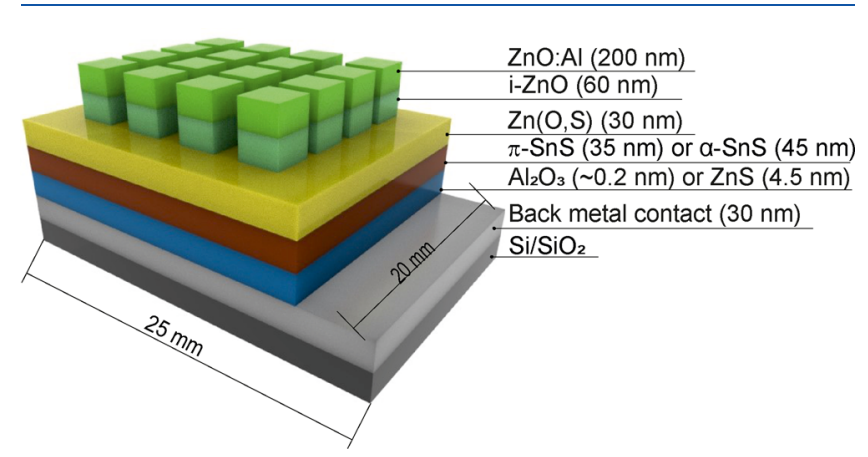

Figure 1. Device configuration comprising 16 individual solar cells with an active area of $0.09 \mathrm{~cm}^{2}$ on a $25 \times 20 \mathrm{~mm} \mathrm{Si}$ substrate. Seeding layers of $\mathrm{Al}_{2} \mathrm{O}_{3}$ and $\mathrm{ZnS}$ were used for effective formation of $\pi$-SnS and $\alpha$-SnS films, respectively.

$\mathrm{Al}_{2} \mathrm{O}_{3}$ or $\mathrm{ZnS}$ seeding layer, an $\pi$ - or $\alpha$-SnS absorber layer, a $\mathrm{Zn}(\mathrm{O}, \mathrm{S})$ buffer layer, and a transparent conducting $\mathrm{i}-\mathrm{ZnO} / \mathrm{ZnO}: \mathrm{Al}$ bilayer. Unless otherwise stated, Mo was used as the back contact. The back metal contacts ( $\mathrm{Mo}, \mathrm{Ti}$, or $\mathrm{Al}$ ) were deposited using pulsed $\mathrm{DC}$ sputtering on Si substrates in a von Ardenne CS 730 S magnetron sputter system. The film thickness was adjusted to $30 \mathrm{~nm}$ for all metals and was controlled by varying the generator power and sputter time. SnS deposition was carried out in a hot-wall Picosun R-200 Advanced ALD system at $120{ }^{\circ} \mathrm{C}$ using alternating injection of the tin(II) acetylacetonate [ $\mathrm{Sn}(\mathrm{acac})_{2}$, Sigma-Aldrich, 99.99\%] precursor and hydrogen sulfide $\left(\mathrm{H}_{2} \mathrm{~S}\right.$, Air Liquide, $\left.99.5 \%\right)$ as the counterreactant.

Nitrogen gas $\left(\mathrm{N}_{2}, 99.9999 \%\right.$, Air Liquide) was used to deliver the precursors to the reactor chamber and to perform intermediate purging steps. As presented in more detail elsewhere, ${ }^{35}$ the polymorph adopted by SnS when grown by ALD can be controlled by the substrate surface in addition to growth temperature and $\mathrm{H}_{2} \mathrm{~S}$ dosing. ${ }^{22}$ In particular, substrates with high surface energy and strong bonding with the $\operatorname{Sn}(\mathrm{acac})$ ligands yield a high content of $\pi$-SnS, while highly hydroxylated substrates or substrates with relatively weak ligand adsorption result in SnS films with a high content of $\alpha$-SnS. In the present work, the back metal contact was modified by either two ALD cycles of $\mathrm{Al}_{2} \mathrm{O}_{3}$ to promote the growth of $\pi$-SnS or by $30 \mathrm{ALD}$ cycles of $\mathrm{ZnS}$ to promote $\alpha$-SnS. These depositions were performed shortly before and at the same temperature $\left(120^{\circ} \mathrm{C}\right)$ as the SnS ALD, under conditions that were previously demonstrated to produce the desired phases. ${ }^{35}$ The $\mathrm{Sn}(\mathrm{acac})_{2}$ source bottle was maintained at $100{ }^{\circ} \mathrm{C}$ to provide sufficient vapor pressure of the liquid precursor and, hence, conditions for saturated SnS growth. This was further enabled by a stop-flow mode of operation. The stop-flow involved a sequence of (1) reduced carrier gas flow, (2) reduced pumping speed through a bypass constriction, (3) precursor injection, (4) precursor exposure, (5) restored pumping speed, and (6) restored carrier gas flow and purging. For the $\operatorname{Sn}(\mathrm{acac})_{2}$ precursor, the duration of steps 1 to 6 was $2,1,1.4,1.6,2$, and $3 \mathrm{~s}$. During this sequence, the carrier gas flow was reduced from 50 to 10 standard cubic centimeters per minute (SCCM) in each of the five unused precursor lines of the system. The $\mathrm{Sn}(\mathrm{acac})_{2}$ line used a flow of $160 \mathrm{SCCM}$ apart from a brief $(1.2 \mathrm{~s})$ boost of 400 SCCM during the injection step. In the $\mathrm{H}_{2} \mathrm{~S}$ half-cycle, the duration of steps 1 to 6 was $1,1,1,2,1$, and 3 s while the $\mathrm{H}_{2} \mathrm{~S}$ line flow was maintained at 120 SCCM. Typically, 1000 SnS ALD cycles were performed, resulting in 35 and $45 \mathrm{~nm}$-thick $\mathrm{SnS}$ films of the cubic and orthorhombic phase, respectively, the thickness difference being due to disparate nucleation behavior of the two cases. ${ }^{35}$ 
Front contact buffer layers consisting of $\mathrm{Zn}(\mathrm{O}, \mathrm{S})$ films with varying sulfur content were also produced by ALD at $120^{\circ} \mathrm{C}$, using diethyl zinc (DEZn, Sigma-Aldrich, $\mathrm{Zn} \geq 52.0 \%$ wt.), deionized water, and $\mathrm{H}_{2} \mathrm{~S}$ (Air Liquide, 99.5\%) sources. A super-cycle was defined where a certain number of $\mathrm{ZnO}$ cycles $\left(\mathrm{DEZn} / \mathrm{N}_{2} / \mathrm{H}_{2} \mathrm{O} / \mathrm{N}_{2}\right)$ were followed by one $\mathrm{ZnS}$ cycle $\left(\mathrm{DEZn} / \mathrm{N}_{2} / \mathrm{H}_{2} \mathrm{~S} / \mathrm{N}_{2}\right)$. The pulse time was set to 0.1 $\mathrm{s}$ for each reactant, whereas the purge times were 3 and $4 \mathrm{~s}$ after the DEZn and $\mathrm{H}_{2} \mathrm{O}\left(\mathrm{H}_{2} \mathrm{~S}\right)$ pulses, respectively. Solar cell areas of $0.3 \mathrm{~cm}$ $\times 0.3 \mathrm{~cm}$ were defined by RF sputtering of approximately $50 \mathrm{~nm}$ i$\mathrm{ZnO}$ and $200 \mathrm{~nm} \mathrm{ZnO:Al} \mathrm{(AZO)} \mathrm{through} \mathrm{a} \mathrm{shadow} \mathrm{mask.} \mathrm{As} \mathrm{a} \mathrm{result,}$ 16 solar cells were created on each substrate (see Figure 1). Alternatively, 25 solar cells with areas of $0.3 \mathrm{~cm} \times 0.3 \mathrm{~cm}$ were defined by photolithography where the cell boundaries were created by etching the device layers down to the back metal contact. Samples made using these two different approaches showed comparable solar cell performance.

2.2. Characterization. Optical constants and thicknesses of the different layers of the device stacks (Figure 1) were determined by means of spectroscopic ellipsometry (SE) using a Woollam RC2 tool. In situ measurement data were acquired every $5 \mathrm{~s}$ at a fixed angle of $61^{\circ}$ during the $\mathrm{ALD}$ of $\mathrm{SnS}$ and $\mathrm{Zn}(\mathrm{O}, \mathrm{S})$, using a wavelength range from 260 to $1690 \mathrm{~nm}$, to characterize film growth and thickness. For the purpose of absorptance calculations, the optical constants of layers in the device stack were characterized ex situ for three angles of incidence $\left(65,70\right.$, and $\left.75^{\circ}\right)$, on samples prepared under similar conditions to those used in measured devices. The optical constants of the fully grown $\alpha$ - and $\pi$-SnS layers were taken from a previous study. ${ }^{22}$ Meanwhile, in situ data of SnS films were modeled by means of oscillator functions as previously described in detail, ${ }^{35}$ with their associated roughness accounted for in a separate layer using the Bruggeman effective medium approximation (EMA). The oscillator parameters plus the filling factor (FF) and depolarization parameter of the EMA were fitted along with the thicknesses of the two SnS-related layers. Roughness at the air-AZO interface was also taken into account by means of a Bruggeman EMA layer.

With the optical constants and layer thicknesses from SE as an input, the transfer matrix method was employed to calculate the electromagnetic fields and absorption in each layer at normal incidence. In the end, minor adjustments of the AZO and roughness layer thicknesses of the model were made to match the external quantum efficiency (EQE) data of an actual $\pi$-SnS device with a $\mathrm{ZnO}$ buffer layer. The resulting optical stack was $25 \mathrm{~nm} \operatorname{EMA}($ air, AZO)/ $190 \mathrm{~nm}$ AZO/60 nm i-ZnO/30 nm ALD-ZnO/5 nm EMA(ZnO, $\pi$ $\mathrm{SnS}) / 35 \mathrm{~nm} \pi$-SnS/30 nm Mo/1.5 nm native $\mathrm{Si}$ oxide/semi-infinite Si. For the $\alpha$-SnS-based devices, the two layers involving $\pi$-SnS were replaced by $15 \mathrm{~nm}$ EMA $(\mathrm{ZnO}, \alpha$-SnS $/ 43 \mathrm{~nm} \alpha$-SnS $)$.

$\mathrm{X}$-ray fluorescence spectrometry (XRF) was employed to determine the composition as expressed by the $S / \mathrm{Zn}$ ratio of the $\mathrm{Zn}(\mathrm{O}, \mathrm{S})$ films. The crystallinity and phase of the $\mathrm{Zn}(\mathrm{O}, \mathrm{S})$ films were estimated by grazing incidence X-ray diffraction (GI-XRD) using a Siemens D5000 instrument equipped with an X-ray mirror and a parallel plate collimator. ${ }^{22}$

The SnS film resistivity was determined using transmission line method (TLM) measurements. ${ }^{36}$ Specially designed TLM electrode structures ${ }^{36}$ were used to interpolate the sheet resistance of the 35 $\mathrm{nm}$-thick $\pi$-SnS films grown under conditions identical to those used for solar cells, but on top of an oxidized Si substrate instead.

2.3. Device Measurements. Device characterization by current density-voltage (JV) measurements in the dark and under simulated sunlight was performed at a fixed temperature of $25{ }^{\circ} \mathrm{C}$ using a custom-built setup with a halogen ELH lamp as the light source. The intensity of the light was calibrated using a Si reference cell. Box plots based on these measurements were generated from the median and quartiles with whiskers defined by the 5th and 95th percentiles, respectively. EQE measurements were performed for selected samples.

2.4. Device Modeling. An analysis of the experimental JV characteristics was performed using the five-parameter single diode equivalent-circuit model, that is,

$$
J=J_{\mathrm{ph}}-J_{0}\left[\exp \left(q \frac{V+J R_{\mathrm{s}}}{A k_{\mathrm{B}} T}\right)-1\right]-\frac{V+J R_{\mathrm{s}}}{R_{\mathrm{p}}}
$$

where $A$ is the ideality factor, $J_{0}$ is $\left[\mathrm{A} \cdot \mathrm{cm}^{-2}\right]$ saturation current density, $R_{\mathrm{p}}$ is $\left[\Omega \cdot \mathrm{cm}^{2}\right]$ parallel resistance, $R_{\mathrm{s}}$ is $\left[\Omega \cdot \mathrm{cm}^{2}\right]$ series resistance, and $J_{\mathrm{ph}}$ is the constant current density source under illumination. The algorithm developed and described in detail by Suckow et al. ${ }^{37}$ was used to fit the JV parameters by minimizing the relative root mean squared error (RMSE) of the model. Data from $V=-0.1 \mathrm{~V}$ to $V=V_{\text {oc }}$ $+0.1 \mathrm{~V}$ were included in the analysis, that is, the range of relevance for solar cell operation.

\section{RESULTS AND DISCUSSION}

3.1. Evaluation of Back Metal Contacts. For $\alpha$-SnS, various metal back contacts have previously been evaluated in theoretical calculations ${ }^{32}$ and experiments, ${ }^{11,36,38}$ with ohmic behavior observed for $\mathrm{Al}, \mathrm{In}, \mathrm{Sn}, \mathrm{Cu}, \mathrm{Zn}, \mathrm{Ti}$, and graphite. Meanwhile, Ni and Mo were found to be less suitable because of unfavorable band alignment and/or inhomogeneities and resistive oxide, resulting in tunneling-assisted recombination. ${ }^{32,38}$ In the case of Mo, it has been argued that the metal sulfide layer which is likely to be formed at the interface of an ALD-grown $(500 \mathrm{~nm}) \mathrm{SnS}$ film and Mo is more favorable for conduction, ${ }^{34}$ and one of the highest efficiencies accomplished in an $\alpha$-SnS solar cell configuration, of $4.4 \%$, did indeed use a Mo back contact. ${ }^{11}$ For $\pi$-SnS, the influence of the metal back contact has been much less researched. Recently, Ahmet et al. compared $\mathrm{Mo}, \mathrm{SnO}_{2}: \mathrm{F}$ (FTO), and FTO with a $20 \mathrm{~nm}$-thick amorphous $\mathrm{TiO}_{x}$ layer $\left(\mathrm{a}-\mathrm{TiO}_{x}\right.$ / FTO) to this end. ${ }^{25} \mathrm{SnS}$ produced by aerosol-assisted chemical vapor deposition on the bare FTO contact showed higher voltage $(144 \mathrm{mV})$ than those with $\mathrm{Mo}(135 \mathrm{mV})$ or a-TiO ${ }_{x} /$ FTO back contacts ( 85 and $133 \mathrm{mV}$ for $\alpha$ - and $\pi$-SnS, respectively). Postannealing of the device at $150{ }^{\circ} \mathrm{C}$ led to improvements with the $\mathrm{a}-\mathrm{TiO}_{x} / \mathrm{FTO}$ contact while samples with Mo degraded because of the formation of shunts.

To investigate the role of the back contact material especially for ultrathin devices based on $\pi$-SnS, we here used sputter deposition to form $30 \mathrm{~nm}$-thick $\mathrm{Mo}, \mathrm{Ti}$, and $\mathrm{Al}$ films on $\mathrm{Si}$ substrates. The sheet resistance was determined by a fourpoint probe to be $\sim 3,15$, and $\sim 1 \Omega$ /sq. for these layers, respectively. The thin layer thickness was chosen to maintain a relatively low roughness. Following the ALD of a substratemodifying layer and $\mathrm{SnS}$, as described in Methods, a front buffer layer was prepared by ALD of $30 \mathrm{~nm} \mathrm{Zn}(\mathrm{O}, \mathrm{S})$ with a sulfur concentration of about 14 atom $\%$ as determined by XRF. A similar composition was previously used to produce the $\alpha$-SnS-based record solar cell of Sinsermsuksakul et al. ${ }^{11}$

Figure 2 depicts the JV curves of samples with $\mathrm{Al}_{2} \mathrm{O}_{3} / \mathrm{Mo}$ in the dark (dashed line) and under illumination with $\mathrm{Mo} / \mathrm{Al}_{2} \mathrm{O}_{3}$, $\mathrm{Ti}, \mathrm{Ti} / \mathrm{Al}_{2} \mathrm{O}_{3}$, and $\mathrm{Al}_{2} \mathrm{O}_{3} / \mathrm{Al}$ back contacts. Although the efficiencies are very low $(\sim 0.01 \%)$ primarily because of the low current densities, a photovoltaic effect is clearly observed for all samples except for devices with $\mathrm{Al}_{2} \mathrm{O}_{3} / \mathrm{Al}$ contacts. The latter had an open circuit voltage and short-circuit current close to zero, which may be associated with the comparably low work function of $\mathrm{Al}$ (below $4.26 \mathrm{eV})^{39}$ leading to the formation of a higher built-in barrier for holes. It could also be that the dense native oxide of the $\mathrm{Al}$ surface forms an insulating layer when combined with the ALD oxide at the back contact interface.

Considering that $\mathrm{SnS}$ deposited on Ti grows predominantly in the cubic phase under our standard ALD conditions, ${ }^{35}$ just as it does on $\mathrm{Al}_{2} \mathrm{O}_{3}$, we compared back contacts of $\mathrm{Ti}$ with and 

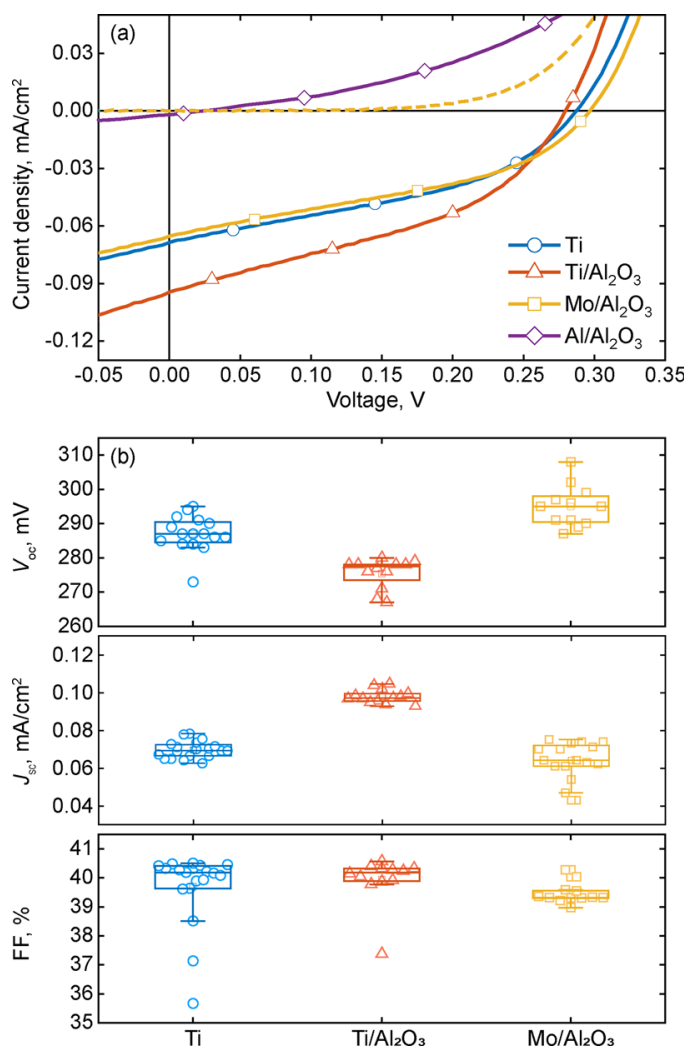

Figure 2. (a) JV characteristics in the dark (dashed line) and under illumination (solid lines) for samples with back contacts of asdeposited $\mathrm{Ti}$ and of $\mathrm{Ti}, \mathrm{Mo}$, and $\mathrm{Al}$ with two ALD cycles of $\mathrm{Al}_{2} \mathrm{O}_{3}$ added. (b) Box plots of JV parameters of the corresponding devices, indicating the median and quartiles along with the 5th and 95th percentiles.

without the two cycles of $\mathrm{Al}_{2} \mathrm{O}_{3}$. The results demonstrate rather similar performances with a slightly greater $J_{s c}$ for the sample with $\mathrm{Al}_{2} \mathrm{O}_{3}$ and a slightly greater $V_{\text {oc }}$ for the sample without $\mathrm{Al}_{2} \mathrm{O}_{3}$. We conclude that the two-cycle $\mathrm{Al}_{2} \mathrm{O}_{3}$ layer does not substantially impact the current extraction at the $\pi$ $\mathrm{SnS}$ back contact in this situation. In terms of solar cell performance, we also find that the sample with an $\mathrm{Al}_{2} \mathrm{O}_{3} / \mathrm{Mo}$ back contact displays similar characteristics to those of samples with $\mathrm{Ti}$ or $\mathrm{Ti} / \mathrm{Al}_{2} \mathrm{O}_{3}$ back contacts despite the differing work functions of the metals $(4.33 \mathrm{eV}$ for Ti vs 4.36 to $4.95 \mathrm{eV}$ for Mo). ${ }^{39}$ Insensitivity to the metal work function may be due to Fermi-level pinning, which results from a reservoir of interfacial midgap states that trap charge at the surface and effectively constrain the Fermi level to within a narrow energy range in the semiconductor bandgap. ${ }^{40}$ Fermi-level pinning has previously been observed for metal/SnS contacts produced in a similar manner. ${ }^{34}$ It is also interesting that the short-circuit current and FF with $\mathrm{Ti}$ are somewhat higher than those for Mo back contacts, the more common choice. To elucidate whether this is due to a passivation of the Ti surface by $\mathrm{Al}_{2} \mathrm{O}_{3}$ or some other effect would require further investigation. Then, we focus on devices with Mo back contacts, for most consistency with previous $\mathrm{SnS}$ solar cell studies.

3.2. Assessment of $\mathrm{Zn}(0, \mathrm{~S})$ Buffer Layers. 3.2.1. Properties of $\mathrm{Zn}(O, S)$ Films on Si. To form a heterojunction with the $\mathrm{SnS}$ absorbers, $\mathrm{Zn}(\mathrm{O}, \mathrm{S})$ buffer layers made by ALD were explored. Compared to CdS, which is often used as a buffer layer in CIGS solar cells, $\mathrm{Zn}(\mathrm{O}, \mathrm{S})$ has the advantages of being a nontoxic, composition- and thereby bandgap-tunable material, which is beneficially grown by ALD. A common scheme for depositing $\mathrm{Zn}(\mathrm{O}, \mathrm{S})$ with a controlled sulfur content is to repeat a super-cycle with a certain number of $\mathrm{ZnO}$ cycles for every cycle of $\mathrm{ZnS} .^{41-43}$ Because the relationship between the $\mathrm{Zn}(\mathrm{O}, \mathrm{S})$ film composition and the ratio of $\mathrm{ZnO}: \mathrm{ZnS}$ ALD cycles depends on both deposition temperature and sample $\mathrm{H}_{2} \mathrm{~S}$ exposure, ${ }^{44}$ we first established the structural and optical properties resulting from our particular ALD process for $\mathrm{Zn}(\mathrm{O}, \mathrm{S})$ coated on polished $\mathrm{Si}$ wafers. Seven different $\mathrm{ZnO}: \mathrm{ZnS}$ cycle ratios were included in a series of samples with film thicknesses kept in the range of 26 to $32 \mathrm{~nm}$ as measured by SE. The resulting XRF-determined atomic ratio of $S$ to $\mathrm{Zn}$ in the $\mathrm{Zn}(\mathrm{O}, \mathrm{S})$ films, equal to the molar fraction of $\mathrm{ZnS}$ for a stoichiometric case (i.e., for compositions $\mathrm{ZnO}_{1-x} \mathrm{~S}_{x}$, $0 \leq x \leq 1)$, is presented in Table 1 , along with the measured $\mathrm{X}$-ray diffraction (XRD) $2 \theta$ peak positions extracted from Figure S1 of the Supporting Information (SI), which agree well with previous results for $\mathrm{Zn}(\mathrm{O}, \mathrm{S})$ films. ${ }^{41}$ Table 1 also includes the SE-determined growth rates, bandgaps, and refractive indexes. From here on, we refer to the XRF-determined $S / Z n$ ratio of the $\mathrm{Zn}(\mathrm{O}, \mathrm{S})$ buffer layer as the "S/Zn ratio."

As seen in Table 1 , the $S / Z n$ ratio exceeds the fraction of $\mathrm{ZnS}$ ALD cycles by far, indicating a nontrivial growth behavior. For example, samples with 94, 48, and $14 \% \mathrm{~S} / \mathrm{Zn}$ ratios resulted from $\mathrm{ZnS}: \mathrm{Zn}(\mathrm{O}, \mathrm{S}) \mathrm{ALD}$ cycle ratios of 50,17 , and $10 \%$, respectively. This tendency toward sulfur enrichment has previously been observed ${ }^{41}$ and shown to be because of the exchange reaction $\mathrm{ZnOH}^{*}+\mathrm{H}_{2} \mathrm{~S} \rightarrow \mathrm{ZnSH}^{*}+\mathrm{H}_{2} \mathrm{O}$, where the star indicates surface species. ${ }^{44}$ Because the reverse reaction is two orders of magnitude slower, the sulfur content of $\mathrm{Zn}(\mathrm{O}, \mathrm{S})$ films exceeds the fraction of cycles with $\mathrm{H}_{2} \mathrm{~S}$ to the total number of cycles.

GI-XRD analysis reveals a polycrystalline nature for most of the studied compositions, with diffraction peaks that are shifting with the concentration, see Table 1 . Such shifts are directly associated with variations of the lattice constants in

Table 1. Properties of Thin $\mathrm{Zn}(\mathrm{O}, \mathrm{S})$ Films Deposited on Si with Varying Sulfur Content

\begin{tabular}{|c|c|c|c|c|c|c|c|c|}
\hline $\begin{array}{l}\mathrm{ZnO}: \mathrm{ZnS} \\
\text { cycle ratio }\end{array}$ & $\begin{array}{l}\mathrm{ZnS}: \mathrm{Zn}(\mathrm{O}, \mathrm{S}) \\
\text { cycle ratio }(\%)\end{array}$ & $\begin{array}{l}\mathrm{XRF} S / \mathrm{Zn} \\
\text { ratio }(\%)\end{array}$ & $\begin{array}{l}\text { total number of } \\
\text { ALD cycles }\end{array}$ & $\begin{array}{c}\text { XRD peak } \\
\text { positions (degrees) }\end{array}$ & $\begin{array}{c}\text { growth rate } \\
(\AA / \text { cycle })\end{array}$ & $\begin{array}{c}\text { direct } \\
\text { bandgap } \\
(\mathrm{eV})\end{array}$ & $\begin{array}{c}\text { indirect } \\
\text { bandgap }(\mathrm{eV})\end{array}$ & $\begin{array}{l}\text { refractive index } \\
\text { at } 1.7 \mathrm{eV}\end{array}$ \\
\hline $1: 0$ & 0 & 0 & 180 & $32.00,34.48,36.32$ & 1.64 & 3.26 & 3.20 & 1.95 \\
\hline $9: 1$ & 10 & 14 & 180 & $31.02,33.23,35.17$ & 1.57 & 3.31 & 3.03 & 1.99 \\
\hline $7: 1$ & 13 & 26 & 200 & $30.84,32.93,34.96$ & 1.59 & 3.42 & 3.00 & 2.01 \\
\hline $5: 1$ & 17 & 48 & 186 & X-ray amorphous & 1.50 & 3.28 & 3.03 & 2.04 \\
\hline $3: 1$ & 25 & 74 & 200 & $\mathrm{X}$-ray amorphous & 1.39 & 3.32 & 3.05 & 2.18 \\
\hline $1: 1$ & 50 & 94 & 200 & 29.11 & 1.34 & 3.18 & 3.00 & 2.28 \\
\hline $0: 1$ & 100 & 100 & 200 & 28.52 & 1.50 & 3.60 & 3.37 & 2.32 \\
\hline
\end{tabular}


$\mathrm{Zn}(\mathrm{O}, \mathrm{S})$, and hence, in accordance with Vegard's law for alloys, ${ }^{45}$ because of changes of the composition. Samples with intermediate compositions of 74 and $48 \% \mathrm{~S} / \mathrm{Zn}$ ratios have no GI-XRD peaks, which indicates an X-ray amorphous structure. This is explained by the transition from the hexagonal $\mathrm{ZnO}$ like phase to the more cubic $\mathrm{ZnS}$-like phase and the associated lattice mismatch. ${ }^{41}$

The growth rates of the $\mathrm{Zn}(\mathrm{O}, \mathrm{S})$ films on $\mathrm{Si}$ were analyzed during growth by in situ SE. The $\mathrm{Zn}(\mathrm{O}, \mathrm{S})$ ALD process requires passivation of the reactor walls if used after ALD of for instance $\mathrm{SnS}$. After 150 passivation cycles of $\mathrm{ZnO}$, no growth delay was observed on $\mathrm{Si}$ substrates. The steady state growth rate decreased from the $1.6 \AA$ /cycle for pure $\mathrm{ZnO}$ to the $1.3 \AA$ / cycle for the 1:1 ALD cycle ratio, after which the growth rate increased again to $1.5 \AA$ /cycle for pure $\mathrm{ZnS}$ (Table 1). The values agree with reported ALD growth rates for $\mathrm{ZnO}^{46}$ and $\mathrm{ZnS}^{47}$ at $120{ }^{\circ} \mathrm{C}$.

3.2.2. Properties of $Z n(O, S)$ Films on $\pi$-SnS. As shown in Figure $S 2$ of the SI, ALD of $\mathrm{Zn}(\mathrm{O}, \mathrm{S})$ exhibits a growth delay on $35 \mathrm{~nm} \pi$-SnS films. This delay is not due to precursor adsorption on the reactor walls, because vacuum was broken and the reactor was passivated by $150 \mathrm{ZnO}$ cycles between the $\pi$-SnS and $\mathrm{Zn}(\mathrm{O}, \mathrm{S})$ runs. Therefore, it is concluded that an incubation period is necessary because of a lack of chemisorption sites for the DEZn precursor on the surface planes exposed by $\pi$-SnS, such that chemisorption may only take place at defects, steps or corner sites, or via surface species such as hydroxyl groups. For a range of $14-74 \% \mathrm{~S} / \mathrm{Zn}$ ratio, the extrapolated nucleation delay is around 40 ALD cycles. The delay leads to an offset in the total thickness, for example, by $6 \mathrm{~nm}$ for the $1.5 \AA / \mathrm{c}$ steady state growth rate of films of $14 \% \mathrm{~S} / \mathrm{Zn}$ ratio, which agrees well with similar observations for pure $\mathrm{ZnO} \mathrm{ALD}$ on gold, $\mathrm{Si}$, and sapphire substrates. ${ }^{46,48} \mathrm{~A}$ nucleation delay was also previously observed for $\mathrm{Zn}(\mathrm{O}, \mathrm{S})$ deposited on CIGS. ${ }^{41}$ After this initial stage, the growth rate on $\pi$-SnS settles to the values observed on the Si substrate to within the margin of error here, of a few percent (see Figure S1b).

The bandgaps of the $\mathrm{Zn}(\mathrm{O}, \mathrm{S})$ films (see Table 1) were determined using extrapolation with the Tauc method ${ }^{49}$ from the absorption coefficients obtained by SE analysis. The observed direct bandgaps of $\mathrm{ZnO}(3.26 \mathrm{eV})$ and $\mathrm{ZnS}(3.6 \mathrm{eV})$ are in good agreement with previous reports. ${ }^{42,44}$ The indirect bandgap values extracted for $\mathrm{Zn}(\mathrm{O}, \mathrm{S})$ films vary in a fairly narrow range from 2.95 to $3.07 \mathrm{eV}$ with a bandgap bowing as a function of composition typical of ternary semiconductor compounds as an effect of charge transfer ${ }^{50}$ and are consistent with the bandgaps observed for $\mathrm{Zn}(\mathrm{O}, \mathrm{S})$ films produced by ALD. ${ }^{44}$ The results also agree well with previous observations of the refractive index at $1.7 \mathrm{eV},{ }^{41}$ which increases monotonically with increasing sulfur content in the $\mathrm{Zn}(\mathrm{O}, \mathrm{S})$ from 1.95 for $\mathrm{ZnO}$ to 2.32 for $\mathrm{ZnS}$.

3.3. Heterojunctions of Varying SnS Phase and $\mathrm{Zn}(\mathrm{O}, \mathrm{S})$ Composition. To compare ultrathin $\pi$-SnS and $\alpha$ $\mathrm{SnS}$ films as solar cell materials, devices were fabricated on Mo back contacts with $30 \mathrm{~nm}$-thick $\mathrm{Zn}(\mathrm{O}, \mathrm{S})$ ALD buffer layers (see Section 2). As everything is common apart from the $\mathrm{SnS}$ phases here, the observable differences are limited in scope and could be further enhanced through optimization of (especially) the relatively unexplored $\pi$-SnS device structure. Apart from the bandgaps and band edge positions, the morphologies of the two SnS polymorphs differ substantially ${ }^{2,35,51}$ and could play a role here. In brief, $\pi$-SnS films consist of densely packed and small $(15-20 \mathrm{~nm})$ grains. Meanwhile, $\alpha$-SnS films show bladelike grains/platelets of random orientation. The latter results in a higher surface roughness of $\alpha$-SnS compared to $\pi$ $\mathrm{SnS}$. Representative JV curves under illumination for devices with $45 \mathrm{~nm} \alpha$-SnS and $35 \mathrm{~nm} \pi$-SnS absorber layers on Mo back contacts are provided in the Supporting Information, Figure S3. It is clear that the JV characteristics depend strongly on the $\mathrm{Zn}(\mathrm{O}, \mathrm{S})$ composition.

3.3.1. Device Performance versus SnS Phase. Statistics for the solar cell parameters of the $\pi$ - and $\alpha$-SnS devices are presented as box plots in Figure 3 and in Table S1 of the

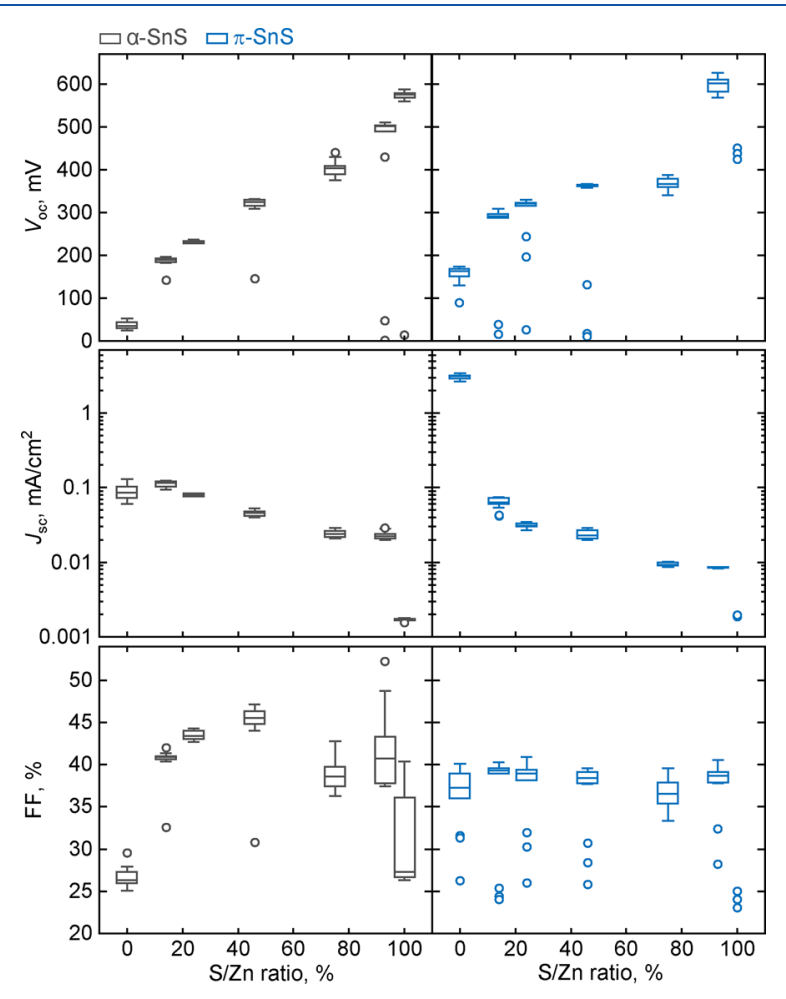

Figure 3. Box plot of JV parameters for heterojunctions based on $\pi$ and $\alpha$-SnS using $\mathrm{Zn}(\mathrm{O}, \mathrm{S})$ buffer layers of varying sulfur content, with the short-circuit currents presented on a logarithmic scale. The boxes are centered on the corresponding $\mathrm{S} / \mathrm{Zn}$ ratio.

Supporting Information. For both $\pi$ - and $\alpha$-SnS, there are two clear, common trends. The $V_{\text {oc }}$ increases with increasing sulfur content in the $\mathrm{Zn}(\mathrm{O}, \mathrm{S})$ and reaches up to about $600 \mathrm{mV}$, which is a very high value in the context of SnS-based solar cells. ${ }^{11,26,33}$ Meanwhile, the $J_{\text {sc }}$ exhibits an opposite, decreasing trend. In comparison with $\alpha$-SnS-based heterojunctions, those with $\pi$-SnS display a more pronounced $V_{\text {oc }}$-plateau for intermediate $S / Z n$ ratios and a more pronounced dependence closer to the extremes of high and low $S / \mathrm{Zn}$ ratios. For the pure $\mathrm{ZnS}$ buffer on $\pi$-SnS, only a few cells had currents above the measurement noise threshold, making the measurement uncertainty high for this particular case.

The general dependence on buffer composition of $J_{\mathrm{sc}}$ and $V_{\mathrm{oc}}$ for buffers with high $\mathrm{S} / \mathrm{Zn}$ ratios may be understood from the corresponding decrease in electron affinity of $\mathrm{Zn}(\mathrm{O}, \mathrm{S})$ and hence the increasing $\mathrm{CBO}$ with $\mathrm{SnS} .^{43,52}$ Sun et al. measured the $\mathrm{CBO}$ of $\alpha$-SnS and $\mathrm{Zn}(\mathrm{O}, \mathrm{S})$ for a range of $\mathrm{Zn}(\mathrm{O}, \mathrm{S})$ compositions. ${ }^{43}$ A CBO around $0.1 \mathrm{eV}$ was measured for a $37 \% \mathrm{~S} / \mathrm{Zn}$ ratio, which increased to above $0.7 \mathrm{eV}$ for a $64 \% \mathrm{~S} /$ $\mathrm{Zn}$ ratio. ${ }^{43} \mathrm{~A}$ detrimental barrier from the $\alpha$-SnS side may thus 
be expected to form somewhere between a 37 and $64 \% \mathrm{~S} / \mathrm{Zn}$ ratio, causing severe limitations in charge transport and an increased $V_{\text {oc }}$ for high $\mathrm{S} / \mathrm{Zn}$ ratios. Such a "spike"-like barrier for photogenerated electrons is commonly found for CIGS and CZTS solar cells with a pure ZnS buffer. ${ }^{41,53}$ This can also explain the blocking effects here observed with $\pi$-SnS. In this scenario, the less distinct voltage dependence observed with $\alpha$ $\mathrm{SnS}$ may result from its higher interfacial roughness and anisotropy, ${ }^{22}$ leading to different surface planes, edges, and corners of varying local potential [and varying interaction/ bonding with the $\mathrm{Zn}(\mathrm{O}, \mathrm{S})$ buffer layer] to contribute to the overall heterojunction properties.

The less distinct dependence on the CBO for $\alpha$-SnS could also be connected to the optically observed band tailing of this polymorph, ${ }^{22}$ which is likely associated with localized states and a locally varying potential distribution over the interface.

For low $\mathrm{S} / \mathrm{Zn}$ ratios, the $\pi$-SnS/ZnO combination gives a significantly higher $J_{\mathrm{sc}}$ of $3.1 \pm 0.2 \mathrm{~mA} / \mathrm{cm}^{2}$, compared to just $0.08 \pm 0.01 \mathrm{~mA} / \mathrm{cm}^{2}$ for $\alpha-\mathrm{SnS} / \mathrm{ZnO}$. The drastic difference is likely due to the lower electron affinity of $\pi$-SnS and a more favorable $\mathrm{CBO},{ }^{54}$ in combination with a better contact to the much more conductive pure $\mathrm{ZnO}^{55}$ (c.f. below). In further support of this, the observation cannot be explained by the generation current density $\left(J_{\text {gen }}\right)$, which is lower for $\pi$-SnS with its wider bandgap ${ }^{22}\left(E_{\mathrm{G}}=1.64 \mathrm{eV}\right)$ compared to $\alpha-\mathrm{SnS}\left(E_{\mathrm{G}}=\right.$ $1.1 \mathrm{eV}$ ). More specifically, for a pure $\mathrm{ZnO}$ buffer layer, the absorption of normal incident light in the $\mathrm{SnS}$ was calculated by means of the transfer matrix method as described in the Experimental Section. In these calculations, the more accurate $^{35}$ optical constants of fully grown $\pi$-SnS and $\alpha$-SnS films obtained from previous variable angle ex situ SE measurements $^{22}$ were deployed. After small adjustments of the thicknesses for the roughness layer and AZO-layer, the absorptance shape agrees well with the measured EQE for the case of $\pi$-SnS (Figure 4), which supports the origin of the photocurrent from the $\pi$-SnS absorber layer. The EQE, in turn, integrates to $3.17 \mathrm{~mA} / \mathrm{cm}^{2}$, which is close to the measured $J_{\mathrm{sc}}$ value. Integration of the calculated absorptance times the AM1.5G solar photon flux for wavelengths up to the bandgap threshold gives $J_{\text {gen }}=8.5 \mathrm{~mA} / \mathrm{cm}^{2}$ with the $35 \mathrm{~nm}$-thick $\pi$-SnS layer and $14.7 \mathrm{~mA} / \mathrm{cm}^{2}$ (based on a $1.64 \mathrm{eV}$ bandgap) with the

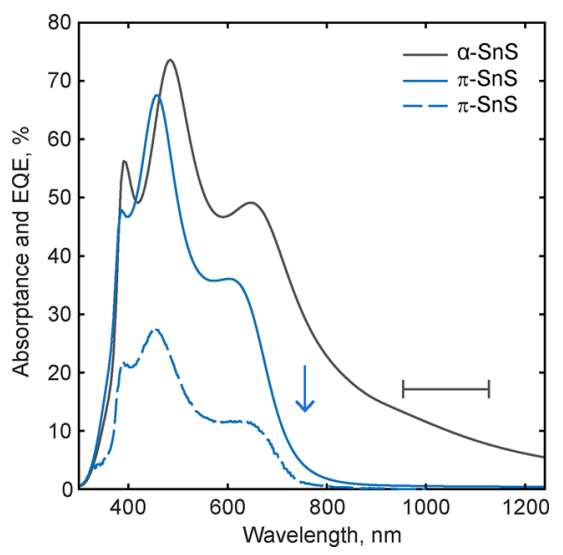

Figure 4. Normal incidence absorptance, calculated based on ellipsometry measurements of the layers in devices with $\mathrm{ZnO}$ buffers. The bandgap of our $\pi$-SnS is indicated by an arrow while a typical range (horizontal bar) is given for the less obvious bandgap of our $\alpha$ $\mathrm{SnS}$, because of its extensive Urbach tail. ${ }^{22}$ The measured EQE for the $\pi$-SnS case is shown by the dashed line.
$45 \mathrm{~nm}$-thick $\alpha$-SnS layer (based on a $1.2 \mathrm{eV} \alpha$-SnS bandgap). The average current collection efficiency $\left(\eta_{\text {coll }}=J_{\text {sc }} / J_{\text {gen }}\right)$ of the $\pi$-SnS/ZnO-devices is thus only $36 \%$. It is an even more severe issue for the $\alpha$-SnS devices with $\eta_{\text {coll }}<1 \%$. As further discussed below, the SnS bulk is likely quasi-neutral and field-free in lack of external bias. With a high recombination velocity at the back contact, this will limit the collection to about $50 \%$, because excited charge carriers will reach either interface with equal probability and also be subject to recombination in the bulk because of poor charge separation. In connection to this, a steep slope of the JV curves can be observed around zero bias (Figure S3), which is likely due to voltage-dependent current collection because many of the samples also display a crossing of the dark and light JV curves (see further below and Figure 5 ). This violation of the superposition principle cannot be explained by mere shunting. ${ }^{56}$ It thus appears that current collection is a quite general issue and consequence of Fermilevel pinning, causing low $J_{\mathrm{sc}}$ for both $\alpha$ - and $\pi$-SnS although less so with a pure $\mathrm{ZnO}$ buffer in the latter case.

The FF for samples with $\pi$-SnS does not vary significantly with sulfur concentration in $\mathrm{Zn}(\mathrm{O}, \mathrm{S})$, and an average around $39 \%$ is observed (Figure 3 and Table S1). For $\alpha$-SnS, on the other hand, the FF is quite irregular. Buffers with low $\mathrm{S} / \mathrm{Zn}$ ratios (0 and $14 \%$ ) result in low FFs around 25\%. For intermediate $S / \mathrm{Zn}$ ratios, the $\mathrm{FF}$ is enhanced to a level comparable to $\pi$-SnS, but for high $S / \mathrm{Zn}$ ratios it then decreases again while the variability increases. In this context, it is noteworthy that $\mathrm{Zn}(\mathrm{O}, \mathrm{S})$ is X-ray amorphous for intermediate $\mathrm{S} / \mathrm{Zn}$ ratios, as established here (Table 1) and in previous studies. ${ }^{41,42,57}$ These amorphous layers will have a smoother surface morphology compared to the crystalline, pure $\mathrm{ZnO}{ }^{58}$ and $\mathrm{ZnS}^{59}$ phases and will thus produce more conformal coatings with improved contact properties-especially on the rough $\alpha$-SnS surface. The smoothing effect of a very finegrained or truly amorphous buffer could be extended to low $S$ / $\mathrm{Zn}$ ratios by sulfur enrichment locally near the $\mathrm{SnS}$ interface, as further discussed below. With this reasoning, the accommodation of roughness would be impaired at high $\mathrm{S} / \mathrm{Zn}$ ratios where the $\mathrm{Zn}(\mathrm{O}, \mathrm{S})$ adopts a higher crystallinity, likely reducing the contact area and leading to lattice mismatch and thereby explaining the less consistent performance of $\alpha$-SnS under these conditions. Meanwhile, contact formation should be less challenging for all $S / \mathrm{Zn}$ ratios in the case of $\pi$-SnS because of its smoother surface morphology ${ }^{22}$ and isotropic crystal structure.

For the thicker $(400 \mathrm{~nm}) \alpha$-SnS absorber layers investigated by Sinsermsuksakul et al., ${ }^{11}$ the highest $4.4 \%$ efficiency was achieved with a $\mathrm{Zn}(\mathrm{O}, \mathrm{S})$ buffer of $14 \% \mathrm{~S} / \mathrm{Zn}$ ratio. In this case, the $\mathrm{Zn}(\mathrm{O}, \mathrm{S}) / \mathrm{SnS}$ interface was modified by ALD of a $1 \mathrm{~nm}$ $\mathrm{SnO}_{2}$ layer while nitrogen doping of the $\mathrm{Zn}(\mathrm{O}, \mathrm{S})$ was used to reduce the carrier concentration, ${ }^{11}$ which was shown to improve the FF and $J_{s c}$. The effect of the $\mathrm{SnO}_{2}$ modification further emphasizes the important role of the $\mathrm{Zn}(\mathrm{O}, \mathrm{S}) / \mathrm{SnS}$ interface quality. We note that the highest $J_{\mathrm{sc}}\left(\sim 0.1 \mathrm{~mA} / \mathrm{cm}^{2}\right)$ for the $\alpha$-SnS devices studied in the present work is found for a $14 \% \mathrm{~S} / \mathrm{Zn}$ ratio in agreement with Sinsermsuksakul et al., ${ }^{11}$ but the $J_{\text {sc }}$ of $\pi$-SnS devices reaches much higher values with a lower sulfur content, that is, with a pure $\mathrm{ZnO}$ buffer giving the highest value of $3.1 \mathrm{~mA} / \mathrm{cm}^{2}$.

3.3.2. Dependence on the $S / Z n$ Ratio for $\pi$-SnS/Zn $(O, S)$ Devices. To gain more insight into the dependence on the buffer layer composition for $\pi$-SnS-based devices in particular, a single diode model was fitted to JV curves representative of 

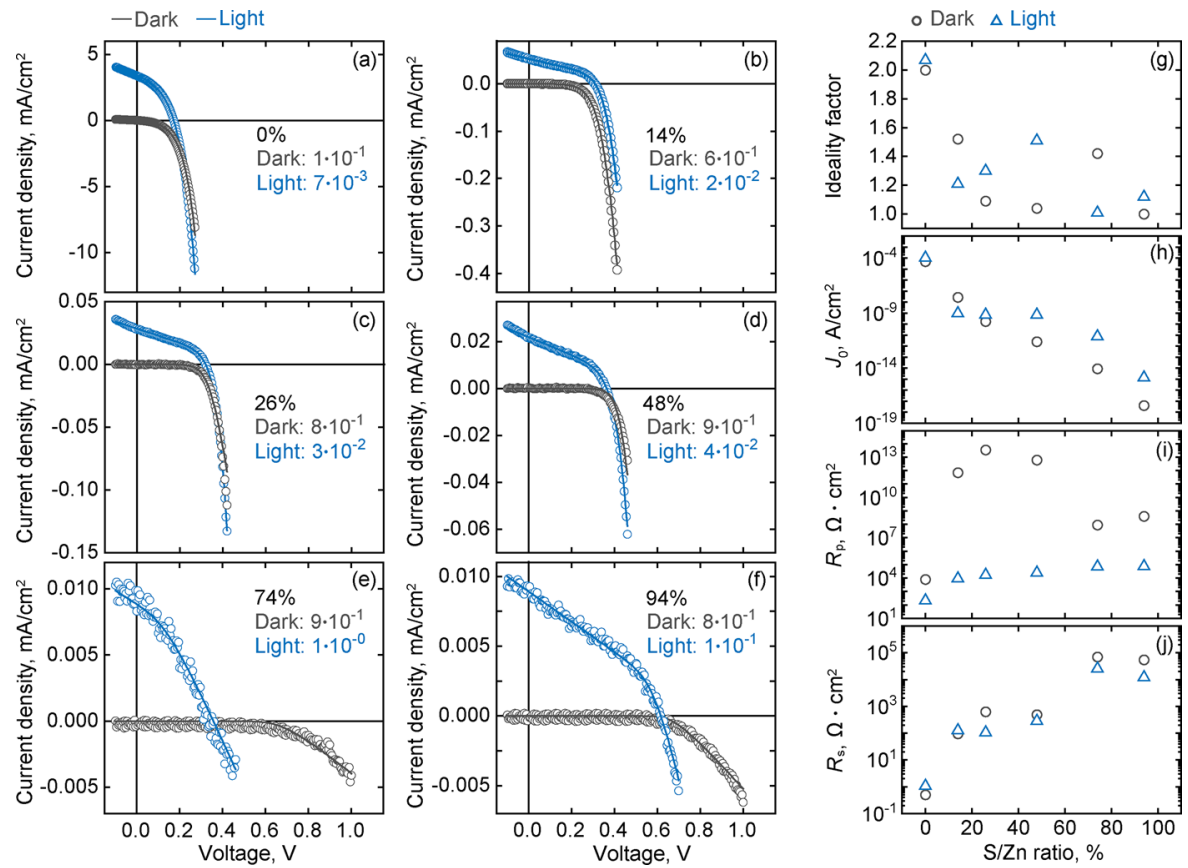

Figure 5. (a-f) Measured (open circles) and fitted (solid lines) JV characteristics of $\pi$-SnS devices with $\mathrm{Zn}(\mathrm{O}, \mathrm{S})$ buffer layers of varying sulfur content. The legends indicate the XRF-determined $\mathrm{S} / \mathrm{Zn}$ ratio in the buffer layer and the relative RMSE for each of the fitted curves. ( $\mathrm{g}-\mathrm{j}$ ) Equivalent-circuit parameters extracted from the JV characteristics under dark and light conditions.

each sample type. The fits are shown in Figure 5 and generally agree well with the measurement data. The relative RMSE values (indicated in the legends of Figure $5 \mathrm{a}-\mathrm{f}$ ) are mainly determined by the signal-to-noise level of the measurements. By studying the parameter dependencies of the model, some observations can be made.

The saturation current, $J_{0}$, is a measure of the overall cell recombination rate, reflecting the cumulative recombination current density via all channels when multiplied by the normalized carrier concentrations $\left(n p / n_{i}^{2}\right){ }^{60}$ The strong drop in the saturation current density $J_{0}$ with the introduction of sulfur in the buffer layer, shown in Figure $5 \mathrm{~g}$, must then be due to reduced recombination. In this context, it is noteworthy that sulfur [i.e., a sulfur-rich phase of $\mathrm{Zn}(\mathrm{O}, \mathrm{S})$ ] has been observed to accumulate near the interface of $\mathrm{Zn}(\mathrm{O}, \mathrm{S}) / \mathrm{CIGS}$ buffer layers. ${ }^{41}$ If such a tendency exists at the $\mathrm{Zn}(\mathrm{O}, \mathrm{S}) / \mathrm{SnS}$ interface as well, it can help explain the rather abrupt change of the behavior with the introduction of only a small amount of sulfur into the buffer. Given the effective sulfur exchange with oxygen previously mentioned, a sulfur-enrichment of the $\mathrm{Zn}(\mathrm{O}, \mathrm{S})$ is expected especially at the bottom of the buffer layer, because the slow initial growth observed for $\mathrm{Zn}(\mathrm{O}, \mathrm{S})$ on $\mathrm{SnS}$, corresponding to a delay of about 40 cycles, will enhance the exposure of any small amounts of grown $\mathrm{ZnO}$ to repeated cycles of $\mathrm{H}_{2} \mathrm{~S}$. Such exchange will be further amplified if the $\mathrm{Zn}(\mathrm{O}, \mathrm{S})$ film is somewhat permeable to the sulfur (or $\mathrm{SH}$ / $\mathrm{H}_{2} \mathrm{~S}$ ) available from the repeated cycles of $\mathrm{H}_{2} \mathrm{~S}$ and to dispelled oxygen $\left(\right.$ or $\left.\mathrm{OH} / \mathrm{H}_{2} \mathrm{O}\right)$. This is clear if considering the extreme case of perfect gas permeability, where the bottom $\mathrm{ZnO}$ sublayer would be exposed to 18 times more sulfur than the topmost $\mathrm{ZnO}$ sublayer under our conditions for the $14 \% \mathrm{~S} / \mathrm{Zn}$ ratio buffer (see Table 1 ). Because the $\mathrm{SnS}$ bulk is unlikely to be affected by additional $\mathrm{H}_{2} \mathrm{~S}$ exposure during $\mathrm{Zn}(\mathrm{O}, \mathrm{S}) \mathrm{ALD}$, the origin of the suppressed recombination of excess carriers generated in the $\mathrm{SnS}$ bulk (and thereby the reduced saturation current) ought to be related to the $\mathrm{SnS} / \mathrm{Zn}(\mathrm{O}, \mathrm{S})$ interface.
The surface recombination can be suppressed through two basic mechanisms, namely, (i) chemical passivation and (ii) field effect passivation. ${ }^{8}$

To determine whether mechanism (i) or (ii) is more plausible here, the ideality factor shown in Figure $5 \mathrm{~h}$ is useful as it reflects the dominant recombination mechanism. It usually takes values in the range of 1 to 2 for regular pn- and heterojunction diodes. A value near 1 implies that the recombination is limited by the minority carrier concentration through a unimolecular process. This is the case in the doped, quasi-neutral region of a device under low injection when recombination occurs via trap states in a Shockley-Read-Hall type of process. Meanwhile, a value closer to 2 results when recombination has bimolecular characteristics, and the product of hole and electron concentrations is rate-determining. ${ }^{61}$ This is typically the case in the depletion region around junctions and contacts of solar cells but may also result under high injection into a quasi-neutral region.

From Figure $5 \mathrm{~h}$, it appears that as soon as some sulfur is introduced into the $\mathrm{Zn}(\mathrm{O}, \mathrm{S})$ buffer layer, the ideality factor drops from a value close to 2 to an intermediate level between 1 and 2 . It drops closer to 1 with higher $S / Z n$ ratios. There are essentially two ways that the recombination mechanism, and hence ideality factor, can change in the present context. The first is through a transition from recombination in a depleted SnS bulk to recombination in a quasi-neutral SnS bulk. The second is through a transition from recombination at the surface to recombination in a quasi-neutral $\mathrm{SnS}$ bulk. The first possibility is, however, contradicted by the reduced overall recombination observed and case (ii) discussed above (for which sulfur leads to passivation through increased rather than reduced depletion), as well as the slightly increased depletion actually measured by Sun et al. for thicker $\alpha$-SnS films with increasing sulfur content of a $\mathrm{Zn}(\mathrm{O}, \mathrm{S})$ buffer. $^{43}$ It would be surprising if the situation with $\pi$-SnS deviates from $\alpha$-SnS in the latter regard, given their relatively similar trends in the JV 
parameters. It thus appears problematic to explain all observations with a field-induced change of the recombination dynamics. This speaks in favor of (i) above, that is, chemical interface passivation.

Chemical passivation will shift the recombination away from bimolecular recombination at the $\pi$-SnS/ $\mathrm{Zn}(\mathrm{O}, \mathrm{S})$ interface toward the $\pi$-SnS bulk. To explain the observed behavior, this must involve a unimolecular type recombination there. Despite the likely low doping levels of these $\pi$-SnS films (see TLM measurements below), a field-free, quasi-neutral bulk with this type of recombination may result if the Fermi energy is pinned at essentially the same energy level on both sides of the $\pi$-SnS film. This would be the case with similar distributions of surface gap states present in sufficiently high density at both the back and front interfaces. Such pinning is then again ruling out field-based explanations for the observed trends. Chemical passivation is, on the other hand, a plausible result of a reduced density of sulfur vacancy-induced gap states and dangling bonds of $\mathrm{Sn}$, which are known to be present in high numbers on the $\pi$-SnS surface. ${ }^{62}$ The interface passivation leads to higher concentrations of excess carriers and thereby contributes to higher open circuit voltages, which is another clear trend from our data with increasing sulfur content (Figure 3).

The different dependencies on the $\mathrm{Zn}(\mathrm{O}, \mathrm{S})$ buffer sulfur content thus lead us to conclude that increasing sulfur content leads to chemical passivation of the $\operatorname{SnS} / \mathrm{Zn}(\mathrm{O}, \mathrm{S})$ interface, which is amplified by the combination of sulfur-oxygen exchange and a $\mathrm{Zn}(\mathrm{O}, \mathrm{S})$ growth delay on $\pi$-SnS.

Turning to the other equivalent-circuit parameters of the single diode model, the constant current density source parameter $J_{\mathrm{ph}}$ fits closely to the measured $J_{\mathrm{sc}}$ (Figure 3 and Figure S4) and thus decreases with the sulfur content of the $\mathrm{Zn}(\mathrm{O}, \mathrm{S})$ buffer. Just as $J_{\mathrm{sc}}$ it is much lower than the generation current density. Such deviation is typically ascribed to recombination during diffusion of excess carriers in the quasi-neutral region of the absorber layer, ${ }^{56}$ consistent with the scenario suggested above. The series resistance parameter $R_{\mathrm{s}}$ extracted from the fitting (Figure $5 \mathrm{j}$ ) displays a sharp increase by two orders of magnitude as soon as a small amount of sulfur is introduced into the buffer layer. We have already seen that pure $\mathrm{ZnS}$ effectively blocks the current for the $\pi$-SnS case and is thus consistent with the formation of a sulfur-rich region of the $\mathrm{Zn}(\mathrm{O}, \mathrm{S})$ near the $\mathrm{SnS}$ interface, a contribution to the series resistance may be observed as well. This could follow from local barriers associated with $\mathrm{ZnS}$ inhomogeneities, or from a continuous but very thin S-rich layer, because the resistivity of $\mathrm{ZnS}$ is around eight orders of magnitude higher than that of $\mathrm{ZnO}$ when produced by low-temperature ALD. ${ }^{55}$

In the ideal diode model, the JV curves in the dark and under illumination differ only by the constant photocurrent source term. This means that the other parameters of the fit should ideally be independent of the illumination conditions. A comparison of the data in Figure $5 \mathrm{~g}-\mathrm{j}$ reveals that this holds up rather well except for the apparent parallel resistance $R_{\mathrm{p}}$, which is much higher in the dark than under illumination for intermediate $\mathrm{S} / \mathrm{Zn}$ ratios. Here, $R_{\mathrm{p}}$ is low under illumination to fit the slope of the JV curve at low bias. However, as mentioned, this does not appear to be because of shunts, as the slope is lacking in the dark JV. Rather, it may be associated with voltage-dependent current collection and poor carrier transport in the $\pi$-SnS bulk, which cannot be accounted for by other parameters of the single diode model.
The picture emerging from the single diode model of our ultrathin devices is thus that the Fermi level is more or less pinned at the front and back interfaces of the $\pi$-SnS absorber layer, leading to inefficient and voltage-dependent carrier transport and current collection. Interface recombination is an important limitation for pure $\mathrm{ZnO}$ buffer layers, but this loss channel is chemically passivated by sulfur. The passivation is likely enhanced through an exchange reaction and associated sulfur enrichment at the $\pi$-SnS interface as soon as small amounts of sulfur are introduced into the buffer. Unfortunately, $\mathrm{ZnS}$ also forms a highly resistive layer with a barrier for current extraction, so that the short-circuit current is reduced drastically already for low $\mathrm{S} / \mathrm{Zn}$ ratios. On the other hand, the combined passivation and spike-like CBO lead to high open circuit voltages for high $S / \mathrm{Zn}$ ratios.

3.4. $\pi$-SnS Resistivity. It is desirable to develop a more comprehensive 1D device model to allow for a detailed understanding of features like the cross-over of the light and dark JV observed in many cases here. However, attempts using SCAPS- $1 D^{63}$ failed to consistently reproduce the observed trends and suffered from a lack of information on basic electrical properties of the $\pi$-SnS layer and its interfaces, leaving a too large parameter space open. More extensive characterization of $\pi$-SnS is therefore desirable, while machine learning strategies have also proven useful to this end. ${ }^{64}$

Characterization of the electronic properties of the ultrathin $\pi$-SnS films was challenging because of their high resistivity. The use of a TLM measurement structure allowed us to determine a sheet resistance of $890 \mathrm{G} \Omega / \mathrm{sq}$. in the dark, corresponding to a resistivity of $3.1 \mathrm{M} \Omega \cdot \mathrm{cm}$ in the direction parallel to the $\pi$-SnS film surface. The contact resistance was too low to discriminate in these measurements. The $\pi$-SnS layers were also too resistive to be measured in our Hall mobility setup. Choi et al. ${ }^{65}$ previously reported Hall measurements on ALD-grown SnS, likely in the form of $\alpha$ $\mathrm{SnS}$ considering the $1.3 \mathrm{eV}$ bandgap and the higher deposition temperature used $\left(170{ }^{\circ} \mathrm{C}\right) .{ }^{65} \mathrm{~A}$ hole mobility of $0.21 \mathrm{~cm}^{2} \mathrm{~V}^{-1}$ $\mathrm{s}^{-1}$ and a carrier concentration of $6 \cdot 10^{16} \mathrm{~cm}^{-3}$ were obtained, ${ }^{65}$ corresponding to a p-type resistivity of close to $500 \Omega \cdot \mathrm{cm} .{ }^{34,65}$ This resistivity is four orders of magnitude lower than that found here, which implies a lower mobility and/or a lower doping concentration in the $\pi$-SnS films of the present work. If assuming that our $\pi$-SnS has a similar mobility, the doping concentration would need to be around $1 \cdot 10^{13} \mathrm{~cm}^{-3}$ from the relation $p^{-1}=\rho e \mu_{\mathrm{h}}$ where $\rho$ is the resistivity, $e$ is the elementary charge, and $\mu_{\mathrm{h}}$ is the hole mobility. If on the other hand assuming that the doping is similar, the mobility would need to be $3 \cdot 10^{-5} \mathrm{~cm}^{2} \mathrm{~V}^{-1} \mathrm{~s}^{-1}$, which would be extremely low compared to other polycrystalline semiconductors. A low effective mobility could be caused by grain boundaries in the lateral plane, implying a higher value in the perpendicular direction. The difference compared to $\alpha$-SnS could also be inherent to the $\pi$-SnS phase or stem from deviations in stoichiometry. ${ }^{22}$ Annealing would likely increase both mobility and carrier concentration. ${ }^{34}$

Photoluminescence measurements with and without encapsulating $\mathrm{Al}_{2} \mathrm{O}_{3}$ (30 ALD cycles deposited without breaking the vacuum after $\pi$-SnS deposition) did not produce any significant peaks. The very low film thickness and likely high densities of bulk and surface trap states may all have contributed to the lack of signal to various degrees.

3.5. Dependence on the ZnO Buffer Layer Thickness. Another important factor for the device performance is the 
buffer layer thickness. To study this, the thickness of pure $\mathrm{ZnO}$ buffer layers was varied from 0 to $50 \mathrm{~nm}$ for devices based on $35 \mathrm{~nm}$ absorber layers of $\pi$-SnS. As seen in Figure 6, both $V_{\text {oc }}$
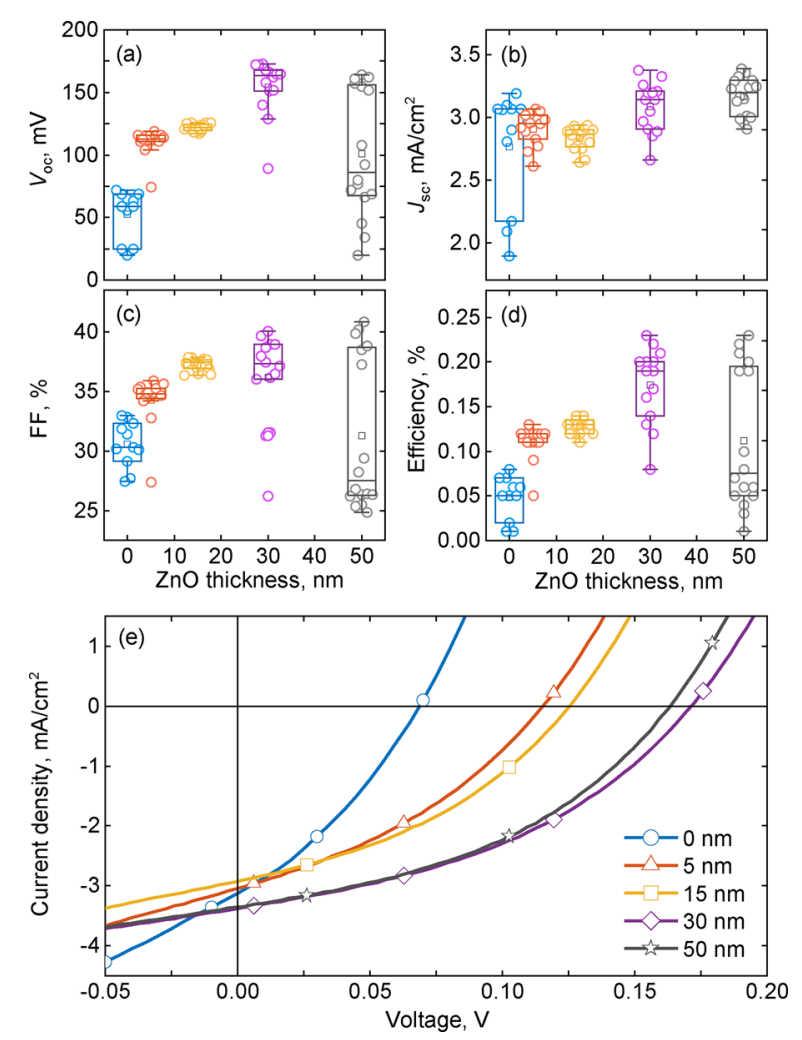

Figure 6. $(\mathrm{a}-\mathrm{d}) \mathrm{JV}$ parameters of $\mathrm{ZnO} / \pi$-SnS heterojunctions with varying $\mathrm{ZnO}$ buffer layer thickness from 0 to $50 \mathrm{~nm}$, measured on 14 \pm 2 cells of each kind. (e) Corresponding JV characteristics of the best cells.

and $\mathrm{FF}$ are very low without the $\mathrm{ZnO}$, that is, when intrinsic $\mathrm{ZnO}$ is sputtered directly on top of the $\pi$-SnS. The efficiency initially increases with buffer layer thickness, with improvements seen in all solar cell parameters. Similar trends have previously been reported with the thickness of CdS buffer layers for $\mathrm{CIGS}^{66,67}$ and $\mathrm{In}_{2} \mathrm{~S}_{3}$ buffer layers for $\mathrm{CZGeSSe}^{68}$ solar cells. The benefits are commonly explained in terms of a reduction of shunts and protection of the heterojunction from sputter-induced damage. In our case, the $V_{\text {oc }}$ and efficiency peak with $30 \mathrm{~nm} \mathrm{ZnO}$. For thicker, $50 \mathrm{~nm}$ buffer layers, the average performance is decreased because of a number of cells showing poor $V_{\mathrm{oc}}$ and FF. The origin of this increased variability with thickness is not evident [although the $\mathrm{Zn}(\mathrm{O}, \mathrm{S})$ grain size could potentially play a role] so we only conclude that no further benefit is observed for a buffer layer thickness beyond $30 \mathrm{~nm}$.

3.6. Dependence on the $\pi$-SnS Layer Thickness. The absorber layer thickness is of obvious importance for the optical absorption, but also for the depth profile of the carrier generation as well as the band diagram of the solar cell. As a final line of investigation, we therefore studied the effect of the $\pi$-SnS thickness. Samples were fabricated with $15,35,75$, and $115 \mathrm{~nm}$ of $\pi$-SnS, and their JV characteristics were measured. A few clear trends versus the $\pi$-SnS thickness can be observed in the statistics for the solar cell parameters shown in the box plots of Figure $7 \mathrm{a}-\mathrm{d}$.
For the three thickest samples, $J_{\mathrm{sc}}$ increases more or less linearly with thickness as one can expect (optically) for very thin films, ${ }^{69}$ although things are somewhat complicated by the substantial interference of the incident light with the wave reflected from the Mo back contact. This leads to deviation from the typical exponential decay of the absorption with depth in the film, as seen in the generation profiles of Figure 7e calculated for normal incident AM1.5G light using the optical properties and thicknesses of all layers in each stack. The overall, integrated generation currents do, nevertheless, show a close to linear trend for the three thickest samples (Figure 7f). The measured $V_{\text {oc }}$ and FF on the other hand show negative trends over the same range (Figure $7 \mathrm{a}, \mathrm{c}$ ). A voltage drop may be expected with increasing absorber layer thickness because of the reduced generation rate per unit volume, here calculated to $4.0,2.4,1.5$, and $1.1 \mathrm{kA} \cdot \mathrm{cm}^{-3}$ in order of increasing thickness. This contributes to lower excess carrier densities, smaller quasi-Fermi-level splitting, and therefore lower voltages.

The collection efficiency, $\eta_{\text {coll }}$, also displays a slightly increasing trend for the three thickest films. This would be expected when back contact recombination is significant and charge carrier generation is more distributed toward the front of thicker films, as is clearly the case here (Figure 7e). A distribution closer to the front increases the likelihood of carriers diffusing into the heterojunction and thereby enhances the charge separation and current collection efficiency.

For the thinnest $\pi$-SnS layer, of $15 \mathrm{~nm}$ thickness, the trends are broken; the $J_{\mathrm{sc}}$ is similar to that of the $35 \mathrm{~nm}$ layer because of a higher collection efficiency, above $50 \%$, but losses in $V_{\text {oc }}$ and FF are also observed. The equivalent-circuit parameters display a very low $R_{\mathrm{p}}$ while $J_{0}$ shows a strong increase, indicative of shunting. A relatively good current collection at short-circuit then rapidly declines because of a high forward current contribution in the operating voltage range of the solar cell. In all of the thicker films, this issue is chiefly resolved, and despite showing the lowest collection efficiency at short-circuit, the $V_{\text {oc }}$ and FF peak for the $35 \mathrm{~nm} \pi$-SnS layer. An optimal $\pi$ $\mathrm{SnS}$ thickness may thus be found in the range of 15 to $35 \mathrm{~nm}$ provided high absorption can be achieved through optical strategies such as plasmonic enhancement. ${ }^{9}$ Yet thinner absorber layers could be viable if the $\pi$-SnS film growth and/ or the back contact could be adapted to eliminate shunting.

3.7. Toward Higher Conversion Efficiency. In closing, we will discuss possible routes toward higher conversion efficiencies as this is, in the end, crucial for photovoltaic applications. In this context, one may note that the highest efficiency found for a $35 \mathrm{~nm} \pi$-SnS layer device, of $0.24 \%$, is more or less in line with a linear extrapolation of the more typical results for SnS-based solar cells (of a few percent efficiency) with varying $\mathrm{SnS}$ film thicknesses up to $525 \mathrm{~nm} .^{15}$ This indicates that the devices studied here essentially perform on a par with typical devices if optical and other thicknessrelated losses are taken into account.

We found the highest efficiencies for a low sulfur content in the $\mathrm{Zn}(\mathrm{O}, \mathrm{S})$ buffer, but also a behavioral divergence between $\alpha$-SnS and $\pi$-SnS devices under these conditions; devices based on $\alpha$-SnS peak around $0.01 \%$ efficiency for a $14 \% \mathrm{~S} / \mathrm{Zn}$ ratio while $\pi$-SnS devices peak at $0.24 \%$ with a pure $\mathrm{ZnO}$ buffer. The difference originates mainly from the short-circuit current which is much higher in the $\pi$-SnS case. We tentatively explain this through the effects of surface roughness and sulfur enrichment on the heterojunction properties. Yet the low collection efficiency below $40 \%$ combined with a low voltage 

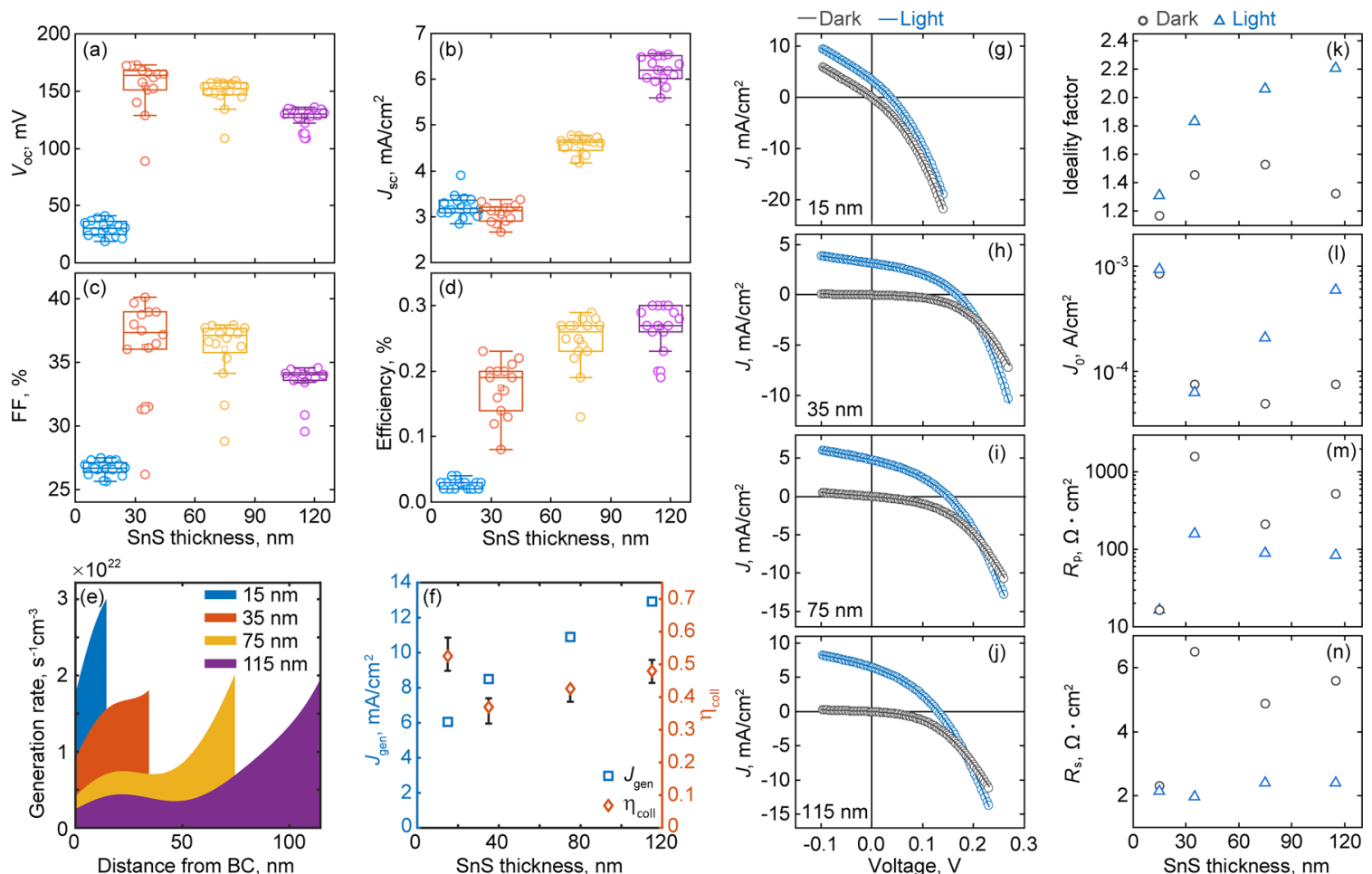

Figure 7. (a-d) Measured solar cell parameters vs $\pi$-SnS thickness. (e) Calculated current generation profiles for normal incident AM1.5G light, vs distance from the back contact. (f) Calculated generation currents and collection efficiencies under short-circuit conditions. (g-j) Representative $\mathrm{JV}$ curves and equivalent-circuit fits (solid lines) for varying $\pi$-SnS thickness. (k-n) Equivalent-circuit parameters from the fits.

emphasizes that more can be gained from these ultrathin $\mathrm{SnS}$ layers, and we identify surface recombination and currentblocking as major limitations in the $\operatorname{SnS} / \mathrm{Zn}(\mathrm{O}, \mathrm{S})$ system.

Clearly, further optimization of interfaces and heterojunction formation is desirable. In the present context, a combination of $\pi$ - and $\alpha$-SnS with $\pi$-SnS acting as a wider bandgap front contact for the $\alpha$-SnS to promote charge separation may be of particular interest. ${ }^{70}$ Preliminary experiments on such heterojunctions were performed using five ALD cycles of $\mathrm{Al}_{2} \mathrm{O}_{3}$ to promote a transition after 500 ALD cycles of $\alpha$-SnS growth, into growth of $\pi$-SnS for 500 cycles. However, as this resulted in current-blocked devices, the concept was not examined in more depth in the present work. Going further, it is also of high interest to further explore tandem configurations through inclusion of an intermediate contact layer between the $\alpha$ - and $\pi$-SnS absorber layers, as their bandgaps complement each other very well for this application. $^{24,25}$

Another important step toward higher efficiency is to attain a more complete light absorption, without impairing the benefits of a high density carrier generation implied by Figure $7 \mathrm{a}, \mathrm{c}$. The use of plasmonic near-field effects by way of free electron-like metal (e.g., $\mathrm{Au}, \mathrm{Ag}, \mathrm{Cu}$, or $\mathrm{Al}$ ) nanoparticle arrays coupled to nanocavity resonances is a promising route, ${ }^{5-7}$ for which high damping semiconductor materials such as $\mathrm{SnS}$ are particularly suitable. ${ }^{6}$ For example, arrays of $\mathrm{Au}$ nanoparticles with SnS coatings have been shown to give up to $60 \%$ absorption of the useful solar spectrum in $\mathrm{SnS}$ coatings as thin as $10 \mathrm{~nm} .^{6}$ One may also envision utilizing such metal nanoparticles for the additional purpose of point contacts to suppress surface recombination. Taken together, solar cells combining ultrathin $\mathrm{SnS}$ absorbers, plasmonics, and tandem structures can be expected to yield much exciting development ahead.

\section{CONCLUSIONS}

For solar cells based on ultrathin $\mathrm{SnS}$ absorbers and $\mathrm{Zn}(\mathrm{O}, \mathrm{S})$ buffer layers, the solar cell parameters show clear trends as a function of buffer layer composition. For the $\pi$-SnS polymorph, the $V_{\text {oc }}$ increases and the $J_{\text {sc }}$ decreases sharply when the $\mathrm{Zn}(\mathrm{O}, \mathrm{S})$ sulfur content is increased from zero to an average concentration around $14 \%$. This is explained by the formation of a sulfur-enriched region of the $\mathrm{Zn}(\mathrm{O}, S)$ near the $\pi$-SnS interface, as further corroborated by trends of the fitted equivalent-circuit parameters. The sulfur enrichment is believed to result from repeated $\mathrm{H}_{2} \mathrm{~S}$ exposure and the known sulfur-oxygen exchange reaction in the ALD of $\mathrm{Zn}(\mathrm{O}, \mathrm{S})$, amplified by the $\sim 40$ cycle growth delay observed for $\mathrm{Zn}(\mathrm{O}, \mathrm{S})$ on $\pi$-SnS. The sulfur chemically passivates the interface, which together with increased $\mathrm{CBO}$ produces an increased $V_{\text {oc }}$ already for low sulfur content in the buffer. However, the increased $\mathrm{CBO}$ also leads to a thin barrier for carrier collection, which explains the reduced short-circuit current. When the sulfur content of the $\mathrm{Zn}(\mathrm{O}, \mathrm{S})$ is further increased, a wider $\mathrm{ZnS}$-like barrier (spike) explains the more pronounced reduction of the $J_{\mathrm{sc}}$ while the $V_{\mathrm{oc}}$ increases further and ultimately reaches around $600 \mathrm{mV}$ for pure $\mathrm{ZnS}$. Compared to $\pi$-SnS, devices with $\alpha$-SnS absorbers show less distinct dependence of the JV parameters on the buffer composition. This is tentatively ascribed to the higher surface roughness and anisotropy of $\alpha$-SnS, leading to different surface planes, edges, and corners of varying local potential to reflect on the effective heterojunction properties. The $\pi$-SnS phase typically generates a somewhat higher open circuit voltage than $\alpha$-SnS for a given buffer composition and a much higher short- 
circuit current density for pure $\mathrm{ZnO}$ buffers. Because of the low, $35 \mathrm{~nm}$ thickness of the $\mathrm{SnS}$ absorber, the efficiency of the cells is low and maximized at $0.24 \%$ for $\pi$-SnS with a pure $\mathrm{ZnO}$ buffer. For the $\alpha$-SnS phase, the optimum $S / Z n$ ratio is rather around $14 \%$, which agrees with previous reports. Because of the sulfur enrichment, a more or less amorphous $\mathrm{Zn}(\mathrm{O}, \mathrm{S})$ phase may form locally near the $\mathrm{SnS}$ interface already at low ALD cycle fractions of sulfur. This would promote a conformal coating and improved contact with especially the rough $\alpha$-SnS surface, as compared to the more crystalline $\mathrm{ZnO}$ buffer. Thereby, the different optima in the buffer sulfur content for $\alpha$ $\mathrm{SnS}$ and $\pi$-SnS may tentatively be explained. We finally conclude that an optimal $\pi$-SnS thickness is found in the range of 15 to $35 \mathrm{~nm}$ given that sufficient absorption can be achieved. To this end, it is promising that arrays of Au nanoparticles with $\mathrm{SnS}$ coatings have been shown to give up to $60 \%$ absorption of the useful solar spectrum in SnS coatings as thin as $10 \mathrm{~nm}^{6}$

\section{ASSOCIATED CONTENT}

\section{SI Supporting Information}

The Supporting Information is available free of charge at https://pubs.acs.org/doi/10.1021/acsaem.1c01375.

$\mathrm{Zn}(\mathrm{O}, \mathrm{S})$ growth on $\mathrm{Si}$ and $\pi$-SnS; solar cell behavior vs $\mathrm{SnS}$ phase and $\mathrm{Zn}(\mathrm{O}, \mathrm{S})$ composition; and current source parameter fit (PDF)

\section{AUTHOR INFORMATION}

\section{Corresponding Author}

Carl Hägglund - Division of Solar Cell Technology, Department of Materials Science and Engineering, Uppsala University, Uppsala SE-751 21, Sweden; 이이.org/00000001-6589-3514; Email: carl.hagglund@angstrom.uu.se

\section{Authors}

Andrii A. Voznyi - Division of Solar Cell Technology, Department of Materials Science and Engineering, Uppsala University, Uppsala SE-751 21, Sweden; Faculty of Electronics and Informational Technologies, Sumy State University, Sumy 40007, Ukraine

Oleksandr V. Bilousov - Division of Solar Cell Technology, Department of Materials Science and Engineering, Uppsala University, Uppsala SE-751 21, Sweden

Björn Landeke-Wilsmark - Division of Solar Cell Technology, Department of Materials Science and Engineering, Uppsala University, Uppsala SE-751 21, Sweden

Jan Keller - Division of Solar Cell Technology, Department of Materials Science and Engineering, Uppsala University, Uppsala SE-751 21, Sweden

Jie Ren - Division of Solid State Electronics, Department of Electrical Engineering, Uppsala University, Uppsala SE-751 21, Sweden; Present Address: Genvida (HK) Co. Ltd., 205, Photonics Centre (2E), Hong Kong Science Park, Pak Shek Kok, N.T., Hong Kong

Shi-Li Zhang - Division of Solid State Electronics, Department of Electrical Engineering, Uppsala University, Uppsala SE751 21, Sweden; (1) orcid.org/0000-0003-2417-274X

Complete contact information is available at:

https://pubs.acs.org/10.1021/acsaem.1c01375

\section{Notes}

The authors declare no competing financial interest.

\section{ACKNOWLEDGMENTS}

We are grateful to Federico Pevere and Tomas Edvinsson for assistance with photoluminescence measurements. Funding from the Swedish Research Council, reg. Number 621-20145599, and the Swedish Energy Agency, project number 454091 , is acknowledged. Myfab is acknowledged for support and for access to the Myfab-Uppsala cleanroom at Uppsala University. A.A.V. acknowledges the Swedish Institute for a guest $\mathrm{PhD}$ scholarship.

\section{REFERENCES}

(1) Chen, H.-L.; Cattoni, A.; De Lépinau, R.; Walker, A. W.; Höhn, O.; Lackner, D.; Siefer, G.; Faustini, M.; Vandamme, N.; Goffard, J.; Behaghel, B.; Dupuis, C.; Bardou, N.; Dimroth, F.; Collin, S. A 19.9\%Efficient Ultrathin Solar Cell Based on a 205-nm-Thick GaAs Absorber and a Silver Nanostructured Back Mirror. Nat. Energy 2019, 4, 761-767.

(2) Brendel, R.; Queisser, H. J. On the Thickness Dependence of Open-Circuit Voltages of P-N-Junction Solar-Cells. Sol. Energy Mater. Sol. Cells 1993, 29, 397-401.

(3) Atwater, H. A.; Polman, A. Plasmonics for Improved Photovoltaic Devices. Nat. Mater. 2010, 9, 205-213.

(4) Jang, Y. H.; Jang, Y. J.; Kim, S.; Quan, L. N.; Chung, K.; Kim, D. H. Plasmonic Solar Cells: From Rational Design to Mechanism Overview. Chem. Rev. 2016, 116, 14982-15034.

(5) Hägglund, C.; Apell, S. P. Plasmonic Near-Field Absorbers for Ultrathin Solar Cells. J. Phys. Chem. Lett. 2012, 3, 1275-1285.

(6) Hägglund, C.; Zeltzer, G.; Ruiz, R.; Wangperawong, A.; Roelofs, K. E.; Bent, S. F. Strong Coupling of Plasmon and Nanocavity Modes for Dual-Band, Near-Perfect Absorbers and Ultrathin Photovoltaics. ACS Photonics 2016, 3, 456-463.

(7) Shi, X.; Ueno, K.; Oshikiri, T.; Sun, Q.; Sasaki, K.; Misawa, H. Enhanced Water Splitting under Modal Strong Coupling Conditions. Nat. Nanotechnol. 2018, 13, 953-958.

(8) Massiot, I.; Cattoni, A.; Collin, S. Progress and Prospects for Ultrathin Solar Cells. Nat. Energy 2020, 5, 959-972.

(9) Hägglund, C.; Apell, S. P. Resource Efficient Plasmon-Based 2DPhotovoltaics with Reflective Support. Opt. Express 2010, 18, A343A356.

(10) Kim, J. Y.; George, S. M. Tin Monosulfide Thin Films Grown by Atomic Layer Deposition Using Tin 2,4-Pentanedionate and Hydrogen Sulfide. J. Phys. Chem. C 2010, 114, 17597-17603.

(11) Sinsermsuksakul, P.; Sun, L.; Lee, S. W.; Park, H. H.; Kim, S. B.; Yang, C.; Gordon, R. G. Overcoming Efficiency Limitations of SnS-Based Solar Cells. Adv. Energy Mater. 2014, 4, No. 1400496.

(12) Andrade-Arvizu, J. A.; Courel-Piedrahita, M.; Vigil-Galán, O. SnS-Based Thin Film Solar Cells: Perspectives Over the Last 25 years. J. Mater. Sci.: Mater. Electron. 2015, 26, 4541-4556.

(13) Di Mare, S.; Menossi, D.; Salavei, A.; Artegiani, E.; Piccinelli, F.; Kumar, A.; Mariotto, G.; Romeo, A. SnS Thin Film Solar Cells: Perspectives and Limitations. Coatings 2017, 7, 34.

(14) Banai, R. E.; Horn, M. W.; Brownson, J. R. S. A Review of Tin (II) Monosulfide and Its Potential as a Photovoltaic Absorber. Sol. Energy Mater. Sol. Cells 2016, 150, 112-129.

(15) Ding, D.; Rath, T.; Lanzetta, L.; Manuel Marin-Beloqui, J.; Haque, S. A. Efficient Hybrid Solar Cells Based on Solution Processed Mesoporous TiO2/Tin(II) Sulfide Heterojunctions. ACS Appl. Energy Mater. 2018, 1, 3042-3047.

(16) Whittles, T. J.; Burton, L. A.; Skelton, J. M.; Walsh, A.; Veal, T. D.; Dhanak, V. R. Band Alignments, Valence Bands, and Core Levels in the Tin Sulfides SnS, SnS2, and Sn2S3: Experiment and Theory. Chem. Mater. 2016, 28, 3718-3726.

(17) Sinsermsuksakul, P.; Heo, J.; Noh, W.; Hock, A. S.; Gordon, R. G. Atomic Layer Deposition of Tin Monosulfide Thin Films. Adv. Energy Mater. 2011, 1, 1116-1125. 
(18) Martí, A.; Araújo, G. L. Limiting Efficiencies for Photovoltaic Energy Conversion in Multigap Systems. Sol. Energy Mater. Sol. Cells 1996, 43, 203-222.

(19) Abutbul, R. E.; Garcia-Angelmo, A. R.; Burshtein, Z.; Nair, M. T. S.; Nair, P. K.; Golan, Y. Crystal Structure of a Large Cubic Tin Monosulfide Polymorph: An Unraveled Puzzle. CrystEngComm 2016, $18,5188-5194$

(20) Abutbul, R. E.; Segev, E.; Zeiri, L.; Ezersky, V.; Makov, G.; Golan, Y. Synthesis and Properties of Nanocrystalline П-SnS - a New Cubic Phase of Tin Sulphide. RSC Adv. 2016, 6, 5848-5855.

(21) Segev, E.; Argaman, U.; Abutbul, R. E.; Golan, Y.; Makov, G. A New Cubic Prototype Structure in the IV-VI Monochalcogenide System: A DFT Study. CrystEngComm 2017, 19, 1751-1761.

(22) Bilousov, O.; Ren, Y.; Törndahl, T.; Donzel-Gargand, O.; Ericson, T.; Platzer-Björkman, C.; Edoff, M.; Hägglund, C. Atomic Layer Deposition of Cubic and Orthorhombic Phase Tin Monosulfide. Chem. Mater. 2017, 29, 2969-2978.

(23) Ahmet, I. Y.; Hill, M. S.; Johnson, A. L.; Peter, L. M. Polymorph-Selective Deposition of High Purity SnS Thin Films from a Single Source Precursor. Chem. Mater. 2015, 27, 7680-7688.

(24) González-Flores, V. E.; Mohan, R. N.; Ballinas-Morales, R.; Nair, M. T. S.; Nair, P. K. Thin Film Solar Cells of Chemically Deposited SnS of Cubic and Orthorhombic Structures. Thin Solid Films 2019, 672, 62-65.

(25) Ahmet, I. Y.; Guc, M.; Sánchez, Y.; Neuschitzer, M.; IzquierdoRoca, V.; Saucedo, E.; Johnson, A. L. Evaluation of AA-CVD Deposited Phase Pure Polymorphs of SnS for Thin Films Solar Cells. RSC Adv. 2019, 9, 14899-14909.

(26) Yun, H.-S.; Park, B.-W.; Choi, Y. C.; Im, J.; Shin, T. J.; Seok, S. I. Efficient Nanostructured $\mathrm{TiO} 2 / \mathrm{SnS}$ Heterojunction Solar Cells. Adv. Energy Mater. 2019, 9, No. 1901343.

(27) Polizzotti, A.; Faghaninia, A.; Poindexter, J. R.; Nienhaus, L.; Steinmann, V.; Hoye, R. L. Z.; Felten, A.; Deyine, A.; Mangan, N. M.; Correa-Baena, J. P.; Shin, S. S.; Jaffer, S.; Bawendi, M. G.; Lo, C.; Buonassisi, T. Improving the Carrier Lifetime of Tin Sulfide Via Prediction and Mitigation of Harmful Point Defects. J. Phys. Chem. Lett. 2017, 8, 3661-3667.

(28) Patel, M.; Chavda, A.; Mukhopadhyay, I.; Kim, J.; Ray, A. Nanostructured SnS with Inherent Anisotropic Optical Properties for High Photoactivity. Nanoscale 2016, 8, 2293-2303.

(29) Spalatu, N.; Hiie, J.; Kaupmees, R.; Volobujeva, O.; Krustok, J.; Oja Acik, I.; Krunks, M. Postdeposition Processing of SnS Thin Films and Solar Cells: Prospective Strategy to Obtain Large, Sintered, and Doped SnS Grains by Recrystallization in the Presence of a Metal Halide Flux. ACS Appl. Mater. Interfaces 2019, 11, 17539-17554.

(30) Lee, D.; Cho, J. Y.; Yun, H.-S.; Lee, D.-K.; Kim, T.; Bang, K.; Lee, Y. S.; Kim, H.-Y.; Heo, J. Vapor Transport Deposited Tin Monosulfide for Thin-Film Solar Cells: Effect of Deposition Temperature and Duration. J. Mater. Chem. A 2019, 7, 7186-7193.

(31) Cho, J. Y.; Sinha, S.; Gang, M. G.; Heo, J. Controlled Thickness of a Chemical-Bath-Deposited CdS Buffer Layer for a SnS Thin Film Solar Cell with More Than 3\% Efficiency. J. Alloys Compd. 2019, 796, $160-166$.

(32) Burton, L. A.; Kumagai, Y.; Walsh, A.; Oba, F. DFT Investigation into the Underperformance of Sulfide Materials in Photovoltaic Applications. J. Mater. Chem. A 2017, 5, 9132-9140.

(33) Schneikart, A.; Schimper, H. J.; Klein, A.; Jaegermann, W. Efficiency Limitations of Thermally Evaporated Thin-Film SnS Solar Cells. J. Phys. D: Appl. Phys. 2013, 46, No. 305109.

(34) Yang, C.; Sun, L.; Brandt, R. E.; Kim, S. B.; Zhao, X.; Feng, J.; Buonassisi, T.; Gordon, R. G. Measurement of Contact Resistivity at Metal-Tin Sulfide (SnS) Interfaces. J. Appl. Phys. 2017, 122, No. 045303.

(35) Bilousov, O. V.; Voznyi, A.; Landeke-Wilsmark, B.; Villamayor, M. M. S.; Nyberg, T.; Hägglund, C. Substrate Effects on Crystal Phase in Atomic Layer Deposition of Tin Monosulfide. Chem. Mater. 2021, 33, 2901-2912.
(36) Devika, M.; Reddy, N. K.; Patolsky, F.; Gunasekhar, K. R. Ohmic Contacts to SnS Films: Selection and Estimation of Thermal Stability. J. Appl. Phys. 2008, 104, 124503.

(37) Suckow, S.; Pletzer, T. M.; Kurz, H. Fast and Reliable Calculation of the Two-Diode Model without Simplifications. Prog. Photovolt.: Res. Appl. 2014, 22, 494-501.

(38) Patel, M.; Ray, A. Evaluation of Back Contact in Spray Deposited SnS Thin Film Solar Cells by Impedance Analysis. ACS Appl. Mater. Interfaces 2014, 6, 10099-10106.

(39) Lide, D. R., Fermi Energy and Related Properties of Metals. 87th ed.; Taylor and Francis: Boca Raton, Fl, 2007.

(40) Tung, R. T. The Physics and Chemistry of the Schottky Barrier Height. Appl. Phys. Rev. 2014, 1, No. 011304.

(41) Platzer-Björkman, C.; Törndahl, T.; Abou-Ras, D.; Malmström, J.; Kessler, J.; Stolt, L. $\mathrm{Zn}(\mathrm{O}, \mathrm{S})$ Buffer Layers by Atomic Layer Deposition in $\mathrm{Cu}(\mathrm{In}, \mathrm{Ga}) \mathrm{Se} 2$ Based Thin Film Solar Cells: Band Alignment and Sulfur Gradient. J. Appl. Phys. 2006, 100, No. 044506.

(42) Bakke, J. R.; Tanskanen, J. T.; Hägglund, C.; Pakkanen, T. A.; Bent, S. F. Growth Characteristics, Material Properties, and Optical Properties of Zinc Oxysulfide Films Deposited by Atomic Layer Deposition. J. Vac. Sci. Technol., A 2012, 30, No. 01A135.

(43) Sun, L.; Haight, R.; Sinsermsuksakul, P.; Bok Kim, S.; Park, H. H.; Gordon, R. G. Band Alignment of $\mathrm{SnS} / \mathrm{Zn}(\mathrm{O}, \mathrm{S})$ Heterojunctions in SnS Thin Film Solar Cells. Appl. Phys. Lett. 2013, 103, 181904.

(44) Lancaster, D. K.; Sun, H.; George, S. M. Atomic Layer Deposition of $\mathrm{Zn}(\mathrm{O}, \mathrm{S})$ Alloys Using Diethylzinc with $\mathrm{H} 2 \mathrm{O}$ and H2S: Effect of Exchange Reactions. J. Phys. Chem. C 2017, 121, 1864318652.

(45) Denton, A. R.; Ashcroft, N. W. Vegard's Law. Phys. Rev. A 1991, 43, 3161-3164.

(46) Yousfi, E. B.; Fouache, J.; Lincot, D. Study of Atomic Layer Epitaxy of Zinc Oxide by in-situ Quartz Crystal Microgravimetry. Appl. Surf. Sci. 2000, 153, 223-234.

(47) Tanskanen, J. T.; Bakke, J. R.; Bent, S. F.; Pakkanen, T. A. ALD Growth Characteristics of ZnS Films Deposited from Organozinc and Hydrogen Sulfide Precursors. Langmuir 2010, 26, 11899-11906.

(48) Lim, J.; Shin, K.; Kim, H.; Lee, C. Enhancement of $\mathrm{ZnO}$ Nucleation in ZnO Epitaxy by Atomic Layer Epitaxy. Thin Solid Films 2005, 475, 256-261.

(49) Tauc, J.; Grigorovici, R.; Vancu, A. Optical Properties and Electronic Structure of Amorphous Germanium. Phys. Status Solidi 1966, 15, 627-637.

(50) Aoumeur-Benkabou, F. Z.; Ameri, M.; Kadoun, A.; Benkabou, $\mathrm{K}$. Theoretical Study on the Origins of the Gap Bowing in MgxZn1xO Alloys. Model. Num. Simul. Mater. Sci. 2012, 02, 60-66.

(51) Segev, E.; Abutbul, R. E.; Argaman, U.; Golan, Y.; Makov, G. Surface Energies and Nanocrystal Stability in the Orthorhombic and $\Pi$-Phases of Tin and Germanium Monochalcogenides. CrystEngComm 2018, 20, 4237-4248.

(52) Persson, C.; Platzer-Björkman, C.; Malmström, J.; Törndahl, T.; Edoff, M. Strong Valence-Band Offset Bowing of $\mathrm{ZnO1-xSx}$ Enhances p-Type Nitrogen Doping of ZnO-Like Alloys. Phys. Rev. Lett. 2006, 97, No. 146403.

(53) Ericson, T.; Scragg, J. J.; Hultqvist, A.; Watjen, J. T.; Szaniawski, P.; Torndahl, T.; Platzer-Bjorkman, C. Zn(O, S) Buffer Layers and Thickness Variations of CdS Buffer for Cu2ZnSnS4 Solar Cells. IEEE J. Photovolt. 2014, 4, 465-469.

(54) Sanal, K. C.; Nair, P. K.; Nair, M. T. S. Band Offset in Zinc Oxy-Sulfide/Cubic-Tin Sulfide Interface from X-Ray Photoelectron Spectroscopy. Appl. Surf. Sci. 2017, 396, 1092-1097.

(55) Jeon, S.; Bang, S.; Lee, S.; Kwon, S.; Jeong, W.; Jeon, H.; Chang, H. J.; Park, H. H. Characteristics of Zinc-Oxide-Sulfide-Mixed Films Deposited by Using Atomic Layer Deposition. J. Korean Phys. Soc. 2008, 53, 3287-3295.

(56) Hegedus, S.; Desai, D.; Thompson, C. Voltage Dependent Photocurrent Collection in $\mathrm{CdTe} / \mathrm{CdS}$ Solar Cells. Prog. Photovolt.: Res. Appl. 2007, 15, 587-602. 
(57) Takabayashi, A.; Iida, S. Composition-Dependent Appearance of Amorphous Phase in $\mathrm{ZnSxO1-x}$ system and Its Stability. Jpn. J. Appl. Phys. 1986, 25, L437-L439.

(58) Cai, J.; Ma, Z.; Wejinya, U.; Zou, M.; Liu, Y.; Zhou, H.; Meng, $\mathrm{X}$. A Revisit to Atomic Layer Deposition of Zinc Oxide Using Diethylzinc and Water as Precursors. J. Mater. Sci. 2019, 54, 52365248.

(59) Mack, J. F.; Van Stockum, P. B.; Yemane, Y. T.; Logar, M.; Iwadate, H.; Prinz, F. B. Observing the Nucleation Phase of Atomic Layer Deposition in situ. Chem. Mater. 2012, 24, 4357-4362.

(60) Cuevas, A. The Recombination Parameter J0. Energy Procedia 2014, 55, 53-62.

(61) Breitenstein, O.; Rißland, S. A Two-Diode Model Regarding the Distributed Series Resistance. Sol. Energy Mater. Sol. Cells 2013, $110,77-86$.

(62) Abutbul, R. E.; Segev, E.; Argaman, U.; Tegze, A.; Makov, G.; Golan, Y. Stability of Cubic Tin Sulphide Nanocrystals: Role of Ammonium Chloride Surfactant Headgroups. Nanoscale 2019, 11, 17104-17110.

(63) Burgelman, M.; Nollet, P.; Degrave, S. Modelling Polycrystalline Semiconductor Solar Cells. Thin Solid Films 2000, 361-362, 527532.

(64) Ren, Z.; Oviedo, F.; Thway, M.; Tian, S. I. P.; Wang, Y.; Xue, H.; Dario Perea, J.; Layurova, M.; Heumueller, T.; Birgersson, E.; Aberle, A. G.; Brabec, C. J.; Stangl, R.; Li, Q.; Sun, S.; Lin, F.; Peters, I. M.; Buonassisi, T. Embedding Physics Domain Knowledge into a Bayesian Network Enables Layer-by-Layer Process Innovation for Photovoltaics. npj Comput. Mater. 2020, 6, 9.

(65) Choi, H.; Lee, J.; Shin, S.; Lee, J.; Lee, S.; Park, H.; Kwon, S.; Lee, N.; Bang, M.; Lee, S.-B.; Jeon, H. Fabrication of High Crystalline SnS and SnS2 Thin Films, and Their Switching Device Characteristics. Nanotechnology 2018, 29, 215201.

(66) Keller, J.; Gustavsson, F.; Stolt, L.; Edoff, M.; Törndahl, T. On the Beneficial Effect of $\mathrm{Al} 2 \mathrm{O} 3$ Front Contact Passivation in $\mathrm{Cu}(\mathrm{In}, \mathrm{Ga}) \mathrm{Se} 2$ Solar Cells. Sol. Energy Mater. Sol. Cells 2017, 159, 189-196.

(67) Löckinger, J.; Nishiwaki, S.; Weiss, T. P.; Bissig, B.; Romanyuk, Y. E.; Buecheler, S.; Tiwari, A. N. TiO2 as Intermediate Buffer Layer in $\mathrm{Cu}(\mathrm{In}, \mathrm{Ga}) \mathrm{Se} 2$ Solar Cells. Sol. Energy Mater. Sol. Cells 2018, 174, 397-404.

(68) Schnabel, T.; Seboui, M.; Bauer, A.; Choubrac, L.; Arzel, L.; Harel, S.; Barreau, N.; Ahlswede, E. Evaluation of Different Buffer Materials for Solar Cells with Wide-Gap Cu2ZnGeSxSe4-x Absorbers. RSC Adv. 2017, 7, 40105-40110.

(69) Hägglund, C.; Apell, S. P.; Kasemo, B. Maximized Optical Absorption in Ultrathin Films and Its Application to Plasmon-Based Two-Dimensional Photovoltaics. Nano Lett. 2010, 10, 3135-3141.

(70) Nair, P. K.; Garcia-Angelmo, A. R.; Nair, M. T. S. Cubic and Orthorhombic SnS Thin-Film Absorbers for Tin Sulfide Solar Cells. Phys. Status Solidi A 2016, 213, 170-177. 